\title{
Summary of the cloud chemistry modeling intercomparison: Photochemical box model simulation
}

\author{
M. C. Barth, ${ }^{1}$ S. Sillman, ${ }^{2}$ R. Hudman, ${ }^{3,4}$ M. Z. Jacobson, ${ }^{5}$ C.-H. Kim, ${ }^{6,7}$ A. Monod, ${ }^{8}$ \\ and J. Liang ${ }^{9}$
}

Received 19 June 2002; revised 13 September 2002; accepted 11 November 2002; published 8 April 2003.

[1] We report results of a cloud chemistry numerical modeling intercomparison, which shows good agreement among gas-aqueous photochemistry box models that are being used in the community. For the case studied, cloud chemistry depleted concentrations of $\mathrm{CH}_{2} \mathrm{O}, \mathrm{CH}_{3} \mathrm{OOH}, \mathrm{HNO}_{3}$, and $\mathrm{O}_{3}$, while $\mathrm{H}_{2} \mathrm{O}_{2}$ (in the absence of sulfur chemistry), $\mathrm{NO}$, and $\mathrm{NO}_{2}$ increased. Because parcels of air usually flow in and out of cloud in a matter of minutes rather than remain in cloud for an hour, an optional simulation was performed in which frequent brief cloud encounters were represented. Representing a cloud intermittently rather than continuously does not alter the total concentration of many of the species. However $\mathrm{CH}_{2} \mathrm{O}$ and $\mathrm{HCOOH}$ concentrations are decreased and increased, respectively, because of the timing of the $\mathrm{CH}_{2} \mathrm{O}$ production during clear-sky intervals and its destruction during cloudy intervals. Further differences between a continuous cloud simulation and an intermittent cloud simulation are expected if $\mathrm{pH}$ is allowed to vary during the cloud periods. Simulating an intermittent cloud brought out the importance of using a chemistry time step that is a multiple of the cloud time step because deviations of results from a simulation in which the chemistry time step did not coincide with the appearance and disappearance of cloud were quite large. To better quantify the effect of cloud on $\mathrm{HO}_{x}$ photochemistry, future investigations should include nonmethane hydrocarbon and sulfur chemistry. Future cloud chemistry modeling intercomparisons should bring in cloud physical and chemical measurements so that the models can be evaluated with observations. INDEX TERMS: 0320 Atmospheric Composition and Structure: Cloud physics and chemistry; 0365 Atmospheric Composition and Structure: Troposphere-composition and chemistry; 0399 Atmospheric Composition and Structure: General or miscellaneous; KEYWORDS: cloud chemistry, photochemical models, tropospheric chemistry

Citation: Barth, M. C., S. Sillman, R. Hudman, M. Z. Jacobson, C.-H. Kim, A. Monod, and J. Liang, Summary of the cloud chemistry modeling intercomparison: Photochemical box model simulation, J. Geophys. Res., 108(D7), 4214, doi:10.1029/2002JD002673, 2003.

\section{Introduction}

[2] Clouds can affect tropospheric chemistry in several ways. Clouds provide a means of transporting constituents found primarily in the boundary layer to the free troposphere. Lightning associated with deep convection produces nitrogen oxides, which has an important effect on ozone chemistry in the upper troposphere. Because clouds scatter

\footnotetext{
${ }^{1}$ National Center for Atmospheric Research, Boulder, Colorado, USA.

${ }^{2}$ University of Michigan, Ann Arbor, Michigan, USA.

${ }^{3}$ University Corporation for Atmospheric Research - Significant Opportunities in Atmospheric Research and Science, Boulder, Colorado, USA.

${ }^{4}$ Now at Harvard University, Cambridge, Massachusetts, USA.

${ }^{5}$ Stanford University, Stanford, California, USA.

${ }^{6}$ Colorado State University, Ft. Collins, Colorado, USA.

${ }^{7}$ Now at National Institute of Environmental Research, Incheon, Korea.

${ }^{8}$ Laboratoire Chimie et Environnement, Marseilles, France.

${ }^{9}$ California Air Resources Board, Sacramento, California, USA.
}

solar radiation, the actinic flux and consequently photodissociation rates are altered above, below, and in clouds. The physics of the interactions between cloud particles can also affect the chemical production and the distribution of chemical species. By producing sulfuric acid, aqueous chemistry increases the acidity of rain, but also affects the net production of other important tropospheric oxidants.

[3] Numerical models serve to synthesize our current understanding of the effect of clouds on tropospheric chemistry, but these models need to be evaluated for their ability to represent individual processes that modify the distribution of chemical species. At the World Meteorological Organization 5th International Cloud Modeling Workshop in August 2000, an intercomparison was conducted of zero-dimensional numerical models that simulated gas and aqueous chemistry and, in some cases, aerosol physics. This intercomparison was broken into two parts, one that focused on gas-aqueous chemistry without aerosols and one that focused on aqueous chemistry as it affects aerosols. Here we present results from the first part, an intercomparison of numerical techniques of the gas-aqueous chemical system 
Table 1. Participants and Features of Their Models

\begin{tabular}{|c|c|c|c|c|c|}
\hline Participant & Solver Type & Time Step & Gas-Aqueous Transport & Aqueous-Phase Dissociation & Ref. $^{\text {a }}$ \\
\hline Barth & Gear & $\leq 4 \mathrm{~min}$ & Diffusion limited & Forward-reverse reactions & G \\
\hline Barth & Euler Backward Iterative (EBI) & $\overline{4} \min$ & Diffusion limited and Equilibrium & Family equilibria & B \\
\hline Jacobson & SMVGEAR & Variable & Diffusion limited & Family equilibria & $\mathrm{J}$ \\
\hline Kim & VODE & $\leq 1 \mathrm{~s}$ & Diffusion limited & Family equilibria & $\mathrm{K}$ \\
\hline Liang & Newton-Raphson (NR) & $5 \mathrm{~min}$ & Diffusion limited and Equilibrium & Family equilibria & LJ \\
\hline Monod & FACSIMILE & $\leq 1 \mathrm{~s}$ & Diffusion limited & Forward-reverse reactions & $\mathrm{C}$ \\
\hline Sillman & Radical Balance Newton-Raphson (RB-NR) & $5 \mathrm{~min}$ & Diffusion limited and Equilibrium & Family equilibria & $\mathrm{S}$ \\
\hline
\end{tabular}

${ }^{a}$ References are G, Gear [1971]; B, Barth et al. [2002]; J, Jacobson [1998]; K, Kim et al. [2002]; LJ, Liang and Jacobson [1999]; C, Chance et al. [1977]; S, Sillman [1991].

and the effect of aqueous chemistry on the total concentration of the species. Results from the second part, an intercomparison of aerosol parcel models, are presented by Kreidenweis et al. [2003].

[4] Because observations of a situation in which aqueous chemistry could be isolated were not available, the focus of the photochemical box model intercomparison is to compare existing gas-aqueous chemistry models to each other while constraining the data so that numerical techniques (both chemistry solver techniques and gas-aqueous transport techniques) used in these models can be evaluated. The results of this intercomparison should indicate how well current gasaqueous chemistry models predict the effect of aqueous chemistry on tropospheric oxidants. Although assessing solution techniques for a gas chemical system has been performed [Olson et al., 1997], the gas-aqueous chemical system offers a more complicated situation because of the shock to the system of equations when cloud water is introduced or removed and because partitioning between phases and between species and their anions must also be represented. To evaluate different numerical techniques, a case study was constructed in which the meteorological parameters, reaction rate coefficients, and solubility coefficients were constrained during a midday 2 hour integration.

[5] To explore more realistic situations, two additional simulations are performed. In the first, the air parcel is exposed to cloud multiple times to learn if the manner in which an air parcel is exposed to cloud affects the chemical species concentration. In the second, the $\mathrm{pH}$ is calculated rather than prescribed to show how some species concentrations strongly depend on the acidity of the cloud drops.

[6] Below we describe the numerical solution techniques that were used for the intercomparison, the conditions of the simulations that were performed, and the results of the comparison and of optional simulations that were done. We discuss the effect of aqueous chemistry on tropospheric oxidant species and suggest topics to address in future cloud chemistry intercomparisons.

\section{Numerical Solution Techniques}

[7] Gas and aqueous chemistry is simulated in models using some form of this first-order, first degree, homogeneous, ordinary differential equation:

$$
\frac{d C}{d t}=P-L C
$$

where $C$ is concentration, $P$ is the chemical production of $C$, and $L$ is the pseudo-first-order loss term of $C$. Here, $C, P$, and $L$ represent vector ensembles of concentrations of individual species, and $P$ and $L$ are functions of $C$. Sets of gas and aqueous chemical reactions are stiff, meaning species whose lifetimes vary by many orders of magnitude, thus only certain numerical solver methods are useful in solving them [Jacobson, 1999]. Table 1 provides information on the numerical solver of the seven models that participated in this case.

\subsection{Ordinary Differential Equations Solvers}

\subsubsection{Gear Solver}

[8] Four models (Barth-Gear, SMVGEAR, VODE, FACSIMILE) use some form of the Gear code [Gear, 1971]. The Gear solver is a very accurate, predictor-corrector method of variable order $s(s<7)$ that is used to solve stiff systems. Concentrations from previous time steps to $t-s \Delta t$, where $\Delta t$ is the time step, are used to optimize the finite difference expression

$$
\frac{d C^{n}}{d t}=\frac{C^{n}-\sum_{j=1}^{s} \alpha_{s, j} C^{n-j}}{\Delta t \beta_{s}} .
$$

where $n$ is the current time step, $n-j$ is the previous $j$ th time step, and $\alpha$ and $\beta$ are scalar multipliers [Jacobson, 1999]. The time step and the order of the method can vary based on the stiffness of the equations in order to optimize computational efficiency given a user-specified error tolerance. For instance, if a concentration is changing quickly the Gear solver reduces the time step to obtain a more accurate solution. The disadvantage of the Gear [1971] method is that it needs to solve large-matrices of partial derivatives, hence limiting its use in large-scale models.

[9] Three models (Barth-Gear, SMVGEAR, VODE) include modifications that increase the speed of calculation. The Barth-Gear solver has Yale sparse matrix package improvements and the VODE solver has a sparse linear algebra implementation [Sandu et al., 1996]. Jacobson and Turco [1994] modified the original Gear code by adding a sparse-matrix package and vectorizing about the grid-cell dimension for SMVGEAR. Jacobson and Turco [1994] also divided the domain into blocks of grid cells with similar stiffness to prevent equations in some regions of the grid from slowing the solution over the entire model domain.

\subsubsection{Euler Backward Iterative}

[10] The Euler backward iterative (EBI) method (Barth$\mathrm{EBI}$ ), which is a stable, implicit method, solves (1) as

$$
C^{n+1, i+1}=\frac{C^{n}+P^{n+1, i} \Delta t}{1+L^{n+1, i} \Delta t}
$$


where $n$ is the current time step, $n+1$ is the next time step, and $i$ represents the number of iterations. Here, $C, P$, and $L$ represent vector ensembles of individual species. Because $P$ and $L$ depend on the concentrations of different species, a Gauss-Seidel procedure is followed: concentrations from the previous time step are used as a first guess to calculate concentrations at the current time step and first iteration; these new concentrations are used to determine $P$ and $L$ for the current time step and next iteration; if all the species have converged (i.e. concentration at the last iteration is nearly the same as that at the previous iteration), then the species' concentrations have been determined for the current time step; otherwise the species concentrations at the last iteration are used to determine $P$ and $L$ and to recalculate equation 3 . This scheme solves and updates equation 3 converging towards an answer for either a fixed number of iterations or, as in Barth-EBI, a threshold convergence criterion. The Barth-EBI method uses $0.01 \%$ for the threshold convergence criterion for all species. In the limit of complete convergence, the EBI method is exactly mass conserving. With the current threshold, it is mass conserving most of the time.

\subsubsection{Newton-Raphson}

[11] The Newton Raphson (NR) method (Liang, Sillman) uses derivatives to converge upon a species concentration at a future time step. Equation (1) is solved as [Liang and Jacobson, 1999],

$$
\begin{gathered}
C^{i+1}-C^{i}=\frac{\Delta t(P-L C)+C^{0}-C^{i}}{I+\Delta t J} \\
J=\frac{\partial(P-L C)}{\partial C}
\end{gathered}
$$

where $I$ denotes the identity matrix. Here, $C, P$, and $L$ are vector ensembles of individual species. The superscripts 0 , $i, i+1$ denote the beginning of a time step, the $\mathrm{i}$-th iteration and the $(\mathrm{i}+1)$-th iteration, respectively. Liang and Jacobson [1999] use sparse-matrix techniques and an iterative approach to solve equations 4 and 5 .

\subsubsection{Radical Balance}

[12] The radical balance (RB) solution technique used by Sillman uses the Newton-Raphson equations 4 and 5 to solve the Euler backward iterative equation 3. This method differs from others in that the inversion of the matrix $(I+$ $\Delta t J)$ in equation 4 is replaced with a solution for $\mathrm{OH}$ and $\mathrm{HO}_{2}$ based on sources and sinks of odd hydrogen radicals [Sillman, 1991]. Species other than $\mathrm{OH}$ and $\mathrm{HO}_{2}$ are solved by applying equations 4 and 5 sequentially to individual species (or for two or three closely related species). This radical balance is equivalent to a sparse-matrix technique for solving equations 4 and 5 but is linked to tropospheric chemistry specifically. For aqueous species, the Sillman model first establishes the gas-aqueous partitioning based on the previous iteration of production and destruction terms. The hydrogen ion concentration is then determined (except in the case where $\mathrm{pH}$ is prescribed) and finally the total concentration of a species is found using equation 4.

\subsection{Transport Across the Gas-Aqueous Interface}

[13] Besides the chemistry solver, the representation of transport across the gas-aqueous interface and of aqueous- phase dissociation may differ amongst models. Barth-Gear, Jacobson, Kim, and Monod determined mass transport limited by diffusion in the gas phase using a droplet radius of $10 \mu \mathrm{m}$ and gas diffusivity of $0.1 \mathrm{~cm}^{2} \mathrm{~s}^{-1}$ and across the drop interface using specified accommodation coefficients (see section 3) [Schwartz, 1986; Lelieveld and Crutzen, 1991]. In FACSIMILE, Monod also calculated aqueousphase mass transport limited by diffusion [Schwartz, 1986] for only aqueous-phase $\mathrm{OH}$.

[14] Barth-EBI and Liang treated most species to be in Henry's Law equilibrium and calculated mass transport in the gas phase and across the interface for a few short-lived species. The algorithm in the Barth-EBI solver calculates the mass transport for $\mathrm{OH}, \mathrm{HO}_{2}, \mathrm{CH}_{3} \mathrm{OO}$, and $\mathrm{HNO}_{3}$. The other species are checked for diffusion limitation in the gas phase and across the interface, but usually are partitioned between gas and aqueous phases according to Henry's law equilibrium. The algorithm in Liang's Newton-Raphson technique calculates the total concentration (gas + aqueous phase concentrations) of $\mathrm{NO}_{2}, \mathrm{NO}$, and $\mathrm{CH}_{2} \mathrm{O}$ and partitions these species between the gas and aqueous phases according to Henry's law equilibrium. The gas and aqueous phases of the other species are predicted separately using mass transport equations.

[15] For the radical balance solution technique, Sillman made the assumption that equation 4 could be solved for the total concentration of each species and that the partitioning of the species between phases can be calculated separately. To determine the partitioning, Sillman assumed that the species in each phase was in steady state so that an aqueous to gas concentration ratio could be found,

$$
\frac{C_{a}}{C_{g}}=K_{H} R T \mathrm{~L} \frac{P_{g}+P_{a}+\frac{L_{g} P_{a}}{k_{t} \mathrm{~L}}}{P_{g}+P_{a}+\frac{K_{H} R T L_{a} P_{g}}{k_{t} \mathrm{~L}}}
$$

where $C_{a}$ and $C_{g}$ are aqueous and gas phase concentrations (molecules $\mathrm{cm}^{-3}$ air), $P_{a}$ and $P_{g}$ are aqueous and gas phase chemical production (molecules $\mathrm{cm}^{-3}$ air s${ }^{-1}$ ), $L_{a}$ and $L_{g}$ are aqueous and gas phase pseudo-first-order chemical loss rates $\left(\mathrm{s}^{-1}\right), K_{H}$ is the Henry's law coefficient $\left(M \mathrm{~atm}^{-1}\right), R(\mathrm{~L}$ atm $\mathrm{mol}^{-1} \mathrm{~K}^{-1}$ ) is the universal gas constant, $T(\mathrm{~K})$ is temperature, $\mathrm{L}\left(\mathrm{cm}^{3} \mathrm{H}_{2} \mathrm{O} \mathrm{\textrm {cm } ^ { - 3 }}\right.$ air) is the liquid water content, and $k_{t}\left(\mathrm{~cm}^{3}\right.$ air $\left.\mathrm{cm}^{-3} \mathrm{H}_{2} \mathrm{O} \mathrm{s}^{-1}\right)$ is the first-order rate constant that represents diffusion through the gas phase and across the interface of the drop (see Schwartz [1986] and Lelieveld and Crutzen [1991] for details of this rate constant). The radical balance technique also included a correction recommended by Lelieveld and Crutzen [1991] for situations in which the average concentration of an aqueous species is limited by the rate of diffusion within the water droplet.

[16] For those species that dissociate in the aqueous phase, Barth-Gear and Monod split these equilibria into forward and reverse reactions (and increased their reaction rates by several orders of magnitude to ensure equilibrium between the species), while others predicted the total concentration in the aqueous phase and partitioned according to the equilibrium constant.

\section{Conditions of the Simulations}

[17] The box model simulation followed case 10 from Lelieveld and Crutzen [1991]. The "box" was placed at 
Table 2. Gas-Phase Reactions

\begin{tabular}{|c|c|c|c|}
\hline Number & Reaction & $\mathrm{k}_{298}{ }^{\mathrm{a}}$ & $-\frac{E}{R}$ \\
\hline (G1) & $\mathrm{O}_{3}+h v \rightarrow \mathrm{O}\left({ }^{1} \mathrm{D}\right)+\mathrm{O}_{2}$ & $4.0 \times 10^{-5}$ & 0.0 \\
\hline (G2) & $\mathrm{O}\left({ }^{1} \mathrm{D}\right)+\mathrm{M} \rightarrow \mathrm{M}+\mathrm{O}_{3}$ & $2.9 \times 10^{-11}$ & -100.0 \\
\hline (G3) & $\mathrm{O}\left({ }^{1} \mathrm{D}\right)+\mathrm{H}_{2} \mathrm{O} \rightarrow 2 \mathrm{OH}$ & $2.2 \times 10^{-10}$ & 0.0 \\
\hline (G4) & $\mathrm{HO}_{2}+\mathrm{O}_{3} \rightarrow \mathrm{OH}+2 \mathrm{O}_{2}$ & $2.0 \times 10^{-15}$ & 500.0 \\
\hline (G5) & $\mathrm{OH}+\mathrm{O}_{3} \rightarrow \mathrm{HO}_{2}+\mathrm{O}_{2}$ & $6.8 \times 10^{-14}$ & 940.0 \\
\hline (G6) & $\mathrm{HO}_{2}+\mathrm{OH} \rightarrow \mathrm{H}_{2} \mathrm{O}+\mathrm{O}_{2}$ & $1.1 \times 10^{-10}$ & -250.0 \\
\hline \multirow[t]{3}{*}{ (G7) } & $\mathrm{HO}_{2}+\mathrm{HO}_{2} \rightarrow \mathrm{H}_{2} \mathrm{O}_{2}+\mathrm{O}_{2}$ & $\mathrm{k}_{a}=1.7 \times 10^{-11 \mathrm{~b}}$ & -600.0 \\
\hline & & $\mathrm{k}_{b}=4.9 \times 10^{-32}$ & -1000.0 \\
\hline & & $\mathrm{k}_{c}=2.24 \times 10^{-18}$ & -2200.0 \\
\hline (G8) & $\mathrm{H}_{2} \mathrm{O}_{2}+h \nu \rightarrow 2 \mathrm{OH}$ & $9.2 \times 10^{-6}$ & 0.0 \\
\hline (G9) & $\mathrm{H}_{2} \mathrm{O}_{2}+\mathrm{OH} \rightarrow \mathrm{HO}_{2}+\mathrm{H}_{2} \mathrm{O}$ & $1.7 \times 10^{-12}$ & 160.0 \\
\hline (G10) & $\mathrm{NO}+\mathrm{O}_{3} \rightarrow \mathrm{NO}_{2}+\mathrm{O}_{2}$ & $1.8 \times 10^{-14}$ & 1400.0 \\
\hline (G11) & $\mathrm{HO}_{2}+\mathrm{NO} \rightarrow \mathrm{OH}+\mathrm{NO}_{2}$ & $8.1 \times 10^{-12}$ & -250.0 \\
\hline (G12) & $\mathrm{NO}_{2}+h \nu \rightarrow \mathrm{NO}+\mathrm{O}_{3}$ & $9.4 \times 10^{-3}$ & 0.0 \\
\hline (G13) & $\mathrm{OH}+\mathrm{NO}_{2}+\mathrm{M} \rightarrow \mathrm{HNO}_{3}+\mathrm{M}$ & $\mathrm{k}_{o}=2.5 \times 10^{-30}\left(\frac{T}{300}\right)^{-4.4}$ & \\
\hline & & $\mathrm{k}_{\infty}=1.6 \times 10^{-11}\left(\frac{T}{300}\right)^{-1.7}$ & \\
\hline (G14) & $\mathrm{HNO}_{3}+h \nu \rightarrow \mathrm{OH}+\mathrm{NO}_{2}$ & $6.5 \times 10^{-7}$ & 0.0 \\
\hline (G15) & $\mathrm{NO}_{2}+\mathrm{O}_{3} \rightarrow \mathrm{NO}_{3}+\mathrm{O}_{2}$ & $3.2 \times 10^{-17}$ & 2500.0 \\
\hline (G16) & $\mathrm{NO}_{3}+h \nu \rightarrow .92 \mathrm{NO}_{2}+.08 \mathrm{NO}+.92 \mathrm{O}_{3}$ & $9.4 \times 10^{-1}$ & 0.0 \\
\hline (G17) & $\mathrm{NO}_{3}+\mathrm{NO} \rightarrow 2 \mathrm{NO}_{2}$ & $2.6 \times 10^{-11}$ & -170.0 \\
\hline (G18) & $\mathrm{NO}_{3}+\mathrm{NO}_{2}+\mathrm{M} \rightarrow \mathrm{N}_{2} \mathrm{O}_{5}+\mathrm{M}$ & $\mathrm{k}_{o}=2.2 \times 10^{-30}\left(\frac{T}{300}\right)^{-3.9}$ & \\
\hline & & $\mathrm{k}_{\infty}=1.5 \times 10^{-12}\left(\frac{T}{300}\right)^{-0.7}$ & \\
\hline (G19) & $\mathrm{N}_{2} \mathrm{O}_{5}+\mathrm{M} \rightarrow \mathrm{NO}_{3}+\mathrm{NO}_{2}+\mathrm{M}$ & $\begin{array}{l}\mathrm{K}_{G 19}=2.9 \times 10^{-11} \\
k=\frac{k_{G 18}}{(1)}\end{array}$ & 11,000 \\
\hline (G20) & $\mathrm{N}_{2} \mathrm{O}_{5}+h \nu \rightarrow \mathrm{NO}_{3}+\mathrm{NO}_{2}$ & $5.1 \times 10^{-5}$ & 0.0 \\
\hline (G21) & $\mathrm{CH}_{4}+\mathrm{OH}+\mathrm{O}_{2} \rightarrow \mathrm{CH}_{3} \mathrm{OO}+\mathrm{H}_{2} \mathrm{O}$ & $6.3 \times 10^{-15}$ & 1800.0 \\
\hline (G22) & $\mathrm{CH}_{3} \mathrm{OO}+\mathrm{NO}+\mathrm{O}_{2} \rightarrow \mathrm{CH}_{2} \mathrm{O}+\mathrm{NO}_{2}+\mathrm{HO}_{2}$ & $7.7 \times 10^{-12}$ & -280.0 \\
\hline (G23) & $\mathrm{CH}_{3} \mathrm{OO}+\mathrm{HO}_{2} \rightarrow \mathrm{CH}_{3} \mathrm{OOH}+\mathrm{O}_{2}$ & $5.6 \times 10^{-12}$ & -800.0 \\
\hline (G24) & $\mathrm{CH}_{3} \mathrm{OO}+\mathrm{HO}_{2} \rightarrow \mathrm{CH}_{2} \mathrm{O}+\mathrm{H}_{2} \mathrm{O}+\mathrm{O}_{2}$ & $2.0 \times 10^{-12}$ & 0.0 \\
\hline (G25) & $\mathrm{CH}_{3} \mathrm{OO}+\mathrm{CH}_{3} \mathrm{OO}+\mathrm{O}_{2} \rightarrow 2 \mathrm{CH}_{2} \mathrm{O}+2 \mathrm{HO}_{2}$ & $4.7 \times 10^{-13}$ & -190.0 \\
\hline (G26) & $\mathrm{CH}_{3} \mathrm{OOH}+h v+\mathrm{O}_{2} \rightarrow \mathrm{CH}_{2} \mathrm{O}+\mathrm{OH}+\mathrm{HO}_{2}$ & $8.7 \times 10^{-6}$ & 0.0 \\
\hline (G27) & $\mathrm{CH}_{3} \mathrm{OOH}+\mathrm{OH} \rightarrow .7 \mathrm{CH}_{3} \mathrm{OO}+.3 \mathrm{CH}_{2} \mathrm{O}+.3 \mathrm{OH}$ & $7.4 \times 10^{-12}$ & -200.0 \\
\hline (G28) & $\mathrm{CH}_{2} \mathrm{O}+h v+2 \mathrm{O}_{2} \rightarrow \mathrm{CO}+2 \mathrm{HO}_{2}$ & $3.6 \times 10^{-5}$ & 0.0 \\
\hline (G29) & $\mathrm{CH}_{2} \mathrm{O}+h \nu \rightarrow \mathrm{CO}+2 \mathrm{H}_{2}$ & $5.0 \times 10^{-5}$ & 0.0 \\
\hline (G30) & $\mathrm{CH}_{2} \mathrm{O}+\mathrm{OH}+\mathrm{O}_{2} \rightarrow \mathrm{CO}+\mathrm{HO}_{2}+\mathrm{H}_{2} \mathrm{O}$ & $1.0 \times 10^{-11}$ & 0.0 \\
\hline (G31) & $\mathrm{CH}_{2} \mathrm{O}+\mathrm{NO}_{3}+\mathrm{O}_{2} \rightarrow \mathrm{CO}+\mathrm{HNO}_{3}+\mathrm{HO}_{2}$ & $5.8 \times 10^{-16}$ & 0.0 \\
\hline (G32) & $\mathrm{CO}+\mathrm{OH}+\mathrm{O}_{2} \rightarrow \mathrm{CO}_{2}+\mathrm{HO}_{2}$ & $2.4 \times 10^{-13}$ & 0.0 \\
\hline (G33) & $\mathrm{HCOOH}+\mathrm{OH}+\mathrm{O}_{2} \rightarrow \mathrm{CO}_{2}+\mathrm{HO}_{2}+\mathrm{H}_{2} \mathrm{O}$ & $4.3 \times 10^{-13}$ & 0.0 \\
\hline
\end{tabular}

${ }^{\mathrm{a}}$ Units for the photolysis frequencies are $\mathrm{s}^{-1}$, for the second-order reaction rate constants are $\mathrm{cm}^{3}$ molecules ${ }^{-1} \mathrm{~s}^{-1}$, and for the third-order reaction rate constants are $\mathrm{cm}^{6}$ molecules $\mathrm{s}^{-2} \mathrm{~s}^{-1}$. Second-order reaction rate constants are of the form $k=k_{298} \exp \left[-\frac{E}{R}\left(\frac{1}{298}-\frac{1}{T}\right)\right]$. Third-order reaction rate constants are of the form $\mathrm{k}=\mathrm{k}_{o}[\mathrm{M}] /(1 .+\kappa) 0.6^{\phi}$ where $\kappa=\mathrm{k}_{o}$ $[\mathrm{M}] / \mathrm{k}_{\infty}, \phi=\left(\left[1+\log _{10}(\kappa)\right]^{2}\right)^{-1}$ and $[\mathrm{M}]$ is the air concentration.

${ }^{\mathrm{b}} \mathrm{Here}$, the rate constant is of the form $k=\left(k_{a}+k_{b}[\mathrm{M}]\right)\left(1+k_{c}\left[\mathrm{H}_{2} \mathrm{O}\right]\right)$ where $\left[\mathrm{H}_{2} \mathrm{O}\right]$ is the water vapor concentration.

$45^{\circ} \mathrm{N}$ and $1.5 \mathrm{~km}$ altitude for summer solstice. Noontime photolysis frequencies and a temperature of $285 \mathrm{~K}$ were held constant throughout the 2 hour integration period. Radiative effects by cloud drop scattering on photolysis frequencies in the air between cloud drops were not considered, but because refraction increases the pathlength inside the drops, in-cloud photolysis frequencies were increased by a factor of 1.5 compared to the gas-phase photolysis. The gas-phase rate constants (Table 2) were updated according to DeMore et al. [1997]. The aqueousphase rate constants (Table 3 ) remained unchanged from those listed by Lelieveld and Crutzen [1991]. The Henry's law equilibrium constants (Table 4) were updated using values listed by R. Sander (Compilation of Henry's law constants for inorganic and organic species of potential importance in environmental chemistry (Version 3), available at http://www.mpch-mainz.mpg.de/sander/res/henry. html, 1999). The accommodation coefficients (Table 5) were those listed by Lelieveld and Crutzen [1991]. The concentrations of fourteen species (Table 5) were predicted.

[18] Two required simulations and two optional simulations were performed (Table 6). The first of the required simulations, which integrates gas-phase chemistry only, is a reference simulation The second required simulation is the standard gas and aqueous-phase chemistry simulation. After 30 minutes of integrating gas-phase chemistry only, a "typical" stratus-type cloud was introduced. The cloud parameters prescribed were $0.3 \mathrm{~g} \mathrm{~m}^{-3}$ of cloud water at $\mathrm{pH}=5$ and droplet radius of $10 \mu \mathrm{m}$. Gas and aqueous-phase chemistry was simulated for one hour. After the hour of cloud exposure, 30 minutes of gas-phase chemistry only was integrated. This simulation conceptually can be viewed as an air parcel entering a cloud after being in clear air for 30 minutes. The parcel remains in the cloud for one hour and then exits. Realistically, the parcel would be activating cloud drops when entering the cloud and evaporating drops when exiting, but we chose to impose the liquid water content rather than to introduce additional differences between participating models. An intercomparison of cloud drop activation and aqueous chemistry is discussed further by Kreidenweis et al. [2003].

[19] The cloudy simulation has two instances of discontinuities (appearance and disappearance of cloud) in the chemical system being solved, while the gas chemistry has none. We therefore expect good agreement among models for the clear sky only simulation. The purposes of performing this simulation are to ensure that good agreement is found and 
Table 3. Aqueous-Phase Reactions ${ }^{\mathrm{a}}$

\begin{tabular}{|c|c|c|c|}
\hline Number & Reaction & $\mathrm{k}_{298}$ & $-\frac{E}{R}$ \\
\hline (A1) & $\mathrm{O}_{3}+\mathrm{h} \nu+\mathrm{H}_{2} \mathrm{O} \rightarrow \mathrm{H}_{2} \mathrm{O}_{2}+\mathrm{O}_{2}$ & $6.0 \times 10^{-5}$ & \\
\hline (A2) & $\mathrm{H}_{2} \mathrm{O}_{2}+\mathrm{h} \nu \rightarrow 2 \mathrm{OH}$ & $1.4 \times 10^{-5}$ & \\
\hline (A3) & $\mathrm{CH}_{2}(\mathrm{OH})_{2}+\mathrm{OH}+\mathrm{O}_{2} \rightarrow \mathrm{HCOOH}+\mathrm{HO}_{2}+\mathrm{H}_{2} \mathrm{O}$ & $2.0 \times 10^{9}$ & -1500 . \\
\hline (A4) & $\mathrm{HCOOH}+\mathrm{OH}+\mathrm{O}_{2} \rightarrow \mathrm{CO}_{2}+\mathrm{HO}_{2}+\mathrm{H}_{2} \mathrm{O}$ & $1.6 \times 10^{8}$ & -1500 . \\
\hline (A5) & $\mathrm{HCOO}^{-}+\mathrm{OH}+\mathrm{O}_{2} \rightarrow \mathrm{CO}_{2}+\mathrm{HO}_{2}+\mathrm{OH}^{-}$ & $2.5 \times 10^{9}$ & -1500 . \\
\hline (A6) & $\mathrm{CH}_{3} \mathrm{OO}+\mathrm{O}_{2}^{-}+\mathrm{H}_{2} \mathrm{O} \rightarrow \mathrm{CH}_{3} \mathrm{OOH}+\mathrm{OH}^{-}+\mathrm{O}_{2}$ & $5.0 \times 10^{7}$ & -1600 . \\
\hline (A7) & $\mathrm{CH}_{3} \mathrm{OOH}+\mathrm{OH} \rightarrow \mathrm{CH}_{3} \mathrm{OO}+\mathrm{H}_{2} \mathrm{O}$ & $2.7 \times 10^{7}$ & -1700 . \\
\hline (A8) & $\mathrm{CH}_{3} \mathrm{OOH}+\mathrm{OH} \rightarrow \mathrm{CH}_{2}(\mathrm{OH})_{2}+\mathrm{OH}$ & $1.9 \times 10^{7}$ & -1900. \\
\hline (A9) & $\mathrm{HO}_{2}+\mathrm{O}_{2}^{-} \rightarrow \mathrm{HO}_{2}^{-}+\mathrm{O}_{2}$ & $1.0 \times 10^{8}$ & -1500 . \\
\hline (A10) & $\mathrm{HO}_{2}^{-}+\mathrm{H}^{+} \rightarrow \mathrm{H}_{2} \mathrm{O}_{2}$ & $5.0 \times 10^{10}$ & -1500 . \\
\hline (A11) & $\mathrm{OH}+\mathrm{OH} \rightarrow \mathrm{H}_{2} \mathrm{O}_{2}$ & $5.2 \times 10^{9}$ & -1500 . \\
\hline (A12) & $\mathrm{O}_{3}+\mathrm{O}_{2}^{-}+\mathrm{H}_{2} \mathrm{O} \rightarrow \mathrm{OH}+2 \mathrm{O}_{2}+\mathrm{OH}^{-}$ & $1.5 \times 10^{9}$ & -1500 . \\
\hline (A13) & $\mathrm{O}_{3}+\mathrm{OH} \rightarrow \mathrm{HO}_{2}+\mathrm{O}_{2}+\mathrm{OH}^{-}$ & $3.0 \times 10^{9}$ & -1500 . \\
\hline (A14) & $\mathrm{H}_{2} \mathrm{O}_{2}+\mathrm{OH} \rightarrow \mathrm{HO}_{2}+\mathrm{H}_{2} \mathrm{O}$ & $2.7 \times 10^{7}$ & -1700 . \\
\hline (A15) & $\mathrm{OH}+\mathrm{O}_{2}^{-} \rightarrow \mathrm{OH}^{-}+\mathrm{O}_{2}$ & $1.0 \times 10^{10}$ & -1500 . \\
\hline (A16) & $\mathrm{HCO}_{3}^{-}+\mathrm{OH} \rightarrow \mathrm{CO}_{3}^{-}+\mathrm{H}_{2} \mathrm{O}$ & $1.0 \times 10^{7}$ & -1500 . \\
\hline (A17) & $\mathrm{HCO}_{3}^{-}+\mathrm{HO}_{2} \rightarrow \mathrm{CO}_{3}^{-}+\mathrm{HO}_{2}^{-}$ & $1.5 \times 10^{6}$ & -1500 . \\
\hline (A18) & $\mathrm{CO}_{3}^{-}+\mathrm{H}_{2} \mathrm{O}_{2} \rightarrow \mathrm{HCO}_{3}^{-}+\mathrm{HO}_{2}$ & $8.0 \times 10^{5}$ & -2800 . \\
\hline (A19) & $\mathrm{CO}_{3}^{-}+\mathrm{O}_{2}^{-} \rightarrow \mathrm{HCO}_{3}^{-}+\mathrm{O}_{2}+\mathrm{OH}^{-}$ & $4.0 \times 10^{8}$ & -1500 \\
\hline (A20) & $\mathrm{HO}_{2}+\mathrm{Cl}_{2}^{-} \rightarrow 2 \mathrm{Cl}^{-}+\mathrm{O}_{2}+\mathrm{H}^{+}$ & $4.5 \times 10^{9}$ & -1500 . \\
\hline (A21) & $\mathrm{O}_{2}^{-}+\mathrm{Cl}_{2}^{-} \rightarrow 2 \mathrm{Cl}^{-}+\mathrm{O}_{2}$ & $1.0 \times 10^{9}$ & -1500 . \\
\hline (A22) & $\mathrm{H}_{2} \mathrm{O}_{2}+\mathrm{Cl}_{2}^{-} \rightarrow 2 \mathrm{Cl}^{-}+\mathrm{HO}_{2}+\mathrm{H}^{+}$ & $1.4 \times 10^{5}$ & -3400 . \\
\hline (A23) & $\mathrm{H}_{2} \mathrm{O}_{2}+\mathrm{Cl} \rightarrow \mathrm{Cl}^{-}+\mathrm{HO}_{2}+\mathrm{H}^{+}$ & $4.5 \times 10^{7}$ & 0 . \\
\hline (A24) & $\mathrm{NO}_{3}+\mathrm{Cl}^{-} \rightarrow \mathrm{NO}_{3}^{-}+\mathrm{Cl}$ & $1.0 \times 10^{8}$ & -1500 \\
\hline (A25) & $\mathrm{NO}_{3}+\mathrm{O}_{2}^{-} \rightarrow \mathrm{NO}_{3}^{-}+\mathrm{O}_{2}$ & $1.0 \times 10^{9}$ & -1500. \\
\hline
\end{tabular}

${ }^{\mathrm{a}}$ Units for the photolysis frequencies are $\mathrm{s}^{-1}$, and for the second-order aqueous reactions are $\mathrm{M}^{-1} \mathrm{~s}^{-1}$. Reaction rates are of the form $k=k_{298} \exp \left[-\frac{E}{R}\left(\frac{1}{T}-\frac{1}{298}\right)\right]$.

to have a reference value for analysis of the effect of aqueous chemistry on atmospheric chemistry. Verwer et al. [1996] suggested that $\sim 10$ discontinuities are appropriate to properly assess the accuracy of each simulation. The cloudy simulation described above does not meet this criterion, however an optional simulation described next does meet this criterion.

[20] The first optional simulation is used to examine the importance of how an air parcel is exposed to cloudy conditions. In the convective boundary layer, an air parcel

Table 4. Equilibrium Coefficients ${ }^{\mathrm{a}}$

\begin{tabular}{|c|c|c|c|}
\hline Number & Reaction & $\mathrm{k}_{298}$ & $-\frac{\Delta H}{R}$ \\
\hline \multicolumn{4}{|c|}{ Henry's Law Equilibria } \\
\hline (E1) & $\mathrm{O}_{3}(\mathrm{~g}) \rightleftharpoons \mathrm{O}_{3}(\mathrm{aq})$ & $1.1 \times 10^{-2}$ & 2300 \\
\hline (E2) & $\mathrm{H}_{2} \mathrm{O}_{2}(\mathrm{~g}) \rightleftharpoons \mathrm{H}_{2} \mathrm{O}_{2}(\mathrm{aq})$ & $8.3 \times 10^{4}$ & 7400 \\
\hline (E3) & $\mathrm{OH}(\mathrm{g}) \rightleftharpoons \mathrm{OH}(\mathrm{aq})$ & 30. & 4500 \\
\hline (E4) & $\mathrm{HO}_{2}(\mathrm{~g}) \rightleftharpoons \mathrm{HO}_{2}(\mathrm{aq})$ & 4. $\times 10^{3}$ & 5900 \\
\hline (E5) & $\mathrm{CH}_{3} \mathrm{OO}(\mathrm{g}) \rightleftharpoons \mathrm{CH}_{3} \mathrm{OO}(\mathrm{aq})$ & 15. & 5600 \\
\hline (E6) & $\mathrm{CH}_{3} \mathrm{OOH}(\mathrm{g}) \rightleftharpoons \mathrm{CH}_{3} \mathrm{OOH}(\mathrm{aq})$ & $3.1 \times 10^{2}$ & 5200 \\
\hline (E7) & $\mathrm{CH}_{2} \mathrm{O}(\mathrm{g}) \rightleftharpoons \mathrm{CH}(\mathrm{OH})_{2}(\mathrm{aq})$ & $3.2 \times 10^{3}$ & 6800 \\
\hline (E8) & $\mathrm{HCOOH}(\mathrm{g}) \rightleftharpoons \mathrm{HCOOH}(\mathrm{aq})$ & $5.4 \times 10^{3}$ & 5700 \\
\hline (E9) & $\mathrm{NO}(\mathrm{g}) \rightleftharpoons \mathrm{NO}(\mathrm{aq})$ & $1.9 \times 10^{-3}$ & 1500 \\
\hline (E10) & $\mathrm{NO}_{2}(\mathrm{~g}) \rightleftharpoons \mathrm{NO}_{2}(\mathrm{aq})$ & $6.4 \times 10^{-3}$ & 2500 \\
\hline (E11) & $\mathrm{HNO}_{3}(\mathrm{~g}) \rightleftharpoons \mathrm{HNO}_{3}(\mathrm{aq})$ & $2.4 \times 10^{6}$ & 8700 \\
\hline$(\mathrm{E} 12)$ & $\mathrm{N}_{2} \mathrm{O}_{5}(\mathrm{~g}) \rightarrow 2 \mathrm{HNO}_{3}(\mathrm{aq})$ & $1.0 \times 10^{12}$ & 0 \\
\hline (E13) & $\mathrm{NO}_{3}(\mathrm{~g}) \rightleftharpoons \mathrm{NO}_{3}(\mathrm{aq})$ & 1.8 & 2000 \\
\hline (E14) & $\mathrm{CO}_{2}(\mathrm{~g}) \rightleftharpoons \mathrm{CO}_{2}(\mathrm{aq})$ & $3.6 \times 10^{-2}$ & 2200 \\
\hline \multicolumn{4}{|c|}{ Acid Dissociation Equilibria } \\
\hline$(\mathrm{E} 15)$ & $\mathrm{H}_{2} \mathrm{O}_{2}(\mathrm{aq}) \rightleftharpoons \mathrm{HO}_{2}^{-}+\mathrm{H}^{+}$ & $2.2 \times 10^{-12}$ & -3700 \\
\hline$(\mathrm{E} 16)$ & $\mathrm{HO}_{2}(\mathrm{aq}) \rightleftharpoons \mathrm{O}_{2}^{-}+\mathrm{H}^{+}$ & $3.5 \times 10^{-5}$ & 0 \\
\hline (E17) & $\mathrm{HCOOH}(\mathrm{aq}) \rightleftharpoons \mathrm{HCOO}^{-}+\mathrm{H}^{+}$ & $1.8 \times 10^{-4}$ & -1500 \\
\hline (E18) & $\mathrm{HNO}_{3}(\mathrm{aq}) \rightleftharpoons \mathrm{NO}_{3}^{-}+\mathrm{H}^{+}$ & 15. & 0 \\
\hline (E19) & $\mathrm{CO}_{2}(\mathrm{aq}) \rightleftharpoons \mathrm{HCO}_{3}^{-}+\mathrm{H}^{+}$ & $4.5 \times 10^{-7}$ & -1000 \\
\hline (E20) & $\mathrm{Cl}_{2}^{-}(\mathrm{aq}) \rightleftharpoons \mathrm{Cl}^{-}+\mathrm{Cl}(\mathrm{aq})$ & $5.3 \times 10^{-6}$ & 0 \\
\hline
\end{tabular}

${ }^{\mathrm{a}}$ Units for solubility constants are $\mathrm{M}$ atm ${ }^{-1}$, and units for dissociation constants are M. Coefficients are of the form $k=k_{298} \exp \left[-\frac{\Delta H}{R}\left(\frac{1}{T}-\frac{1}{298}\right)\right]$ unless otherwise noted. follows large eddies that move from the surface to the top of the boundary layer where a cloud may reside then back to the surface. For this situation an air parcel is in cloud for only tens of minutes rather than an hour. Thus, this optional simulation is designed to mimic an air parcel moving in and out of cloud. After 30 minutes of clear air, the air parcel encounters 10 minutes of cloudy, non-cloudy intervals until a total of one-hour of cloudy air is reached (Table 6). Clear air chemistry is included for the remainder of the run. By having 6 cloudy intervals, the number of discontinuities encountered are 12. Thus, this intermittent cloud simulation should reveal any weaknesses among the model techniques employed. Not only is this simulation more realistic, it is also the first time that an intercomparison has been performed on such a case. Sandu et al. [1997] compare several numerical solvers for the

Table 5. Accommodation Coefficients and Initial Concentrations of the Species

\begin{tabular}{|c|c|c|}
\hline Species & Accommodation Coefficient & Initial Concentration \\
\hline $\mathrm{O}_{3}$ & 0.00053 & $40 \mathrm{ppbv}$ \\
\hline $\mathrm{H}_{2} \mathrm{O}_{2}$ & 0.02 & $1 \mathrm{ppbv}$ \\
\hline $\mathrm{OH}$ & 0.05 & $0.162 \mathrm{pptv}$ \\
\hline $\mathrm{HO}_{2}$ & 0.20 & $16.2 \mathrm{pptv}$ \\
\hline $\mathrm{CH}_{3} \mathrm{OO}$ & 0.05 & 0.0 \\
\hline $\mathrm{CH}_{3} \mathrm{OOH}$ & 0.05 & $0.2 \mathrm{ppbv}$ \\
\hline $\mathrm{CH}_{2} \mathrm{O}$ & 0.05 & $0.45 \mathrm{ppbv}$ \\
\hline $\mathrm{HCOOH}$ & 0.05 & 0.0 \\
\hline NO & 0.005 & 0.0 \\
\hline $\mathrm{NO}_{2}$ & 0.00063 & $0.135 \mathrm{ppbv}$ \\
\hline $\mathrm{HNO}_{3}$ & 0.05 & $0.1 \mathrm{ppbv}$ \\
\hline $\mathrm{N}_{2} \mathrm{O}_{5}$ & 0.05 & 0.0 \\
\hline $\mathrm{NO}_{3}$ & 0.001 & 0.0 \\
\hline $\mathrm{CO}_{2}$ & 0.05 & $350 \mathrm{ppmv}$ \\
\hline $\mathrm{H}_{2}$ & $\ldots$ & $550 \mathrm{ppbv}$ \\
\hline $\mathrm{H}_{2} \mathrm{O}$ & $\ldots$ & $10.25 \mathrm{~g} \mathrm{~kg}^{-1}$ \\
\hline $\mathrm{CH}_{4}$ & $\ldots$ & $1700 \mathrm{ppbv}$ \\
\hline $\mathrm{CO}$ & & 90 ppbv \\
\hline
\end{tabular}


Table 6. Simulations Performed for the Intercomparison

\begin{tabular}{lcc}
\hline \multicolumn{1}{c}{ Simulation } & Integration Time & Time in Cloud \\
\hline & Required Simulations & \\
Clear Air & 2 hours $(1100-1300)$ & None \\
Cloudy (standard) & 2 hours & $1130-1230$ \\
& & \\
& Optional Simulations & \\
Intermittent cloud & 2.8 hours & One hour (see text) \\
Varying pH & 2 hours & $1130-1230$ \\
\hline
\end{tabular}

gas-aqueous chemistry system, but the liquid water content did not change during the integration period.

[21] The second optional simulation is the same as the standard cloudy simulation except that the $\mathrm{pH}$ is allowed to vary as the chemical reactions proceed. The $\mathrm{pH}$ is determined from the charge balance of the cations and anions listed in Tables 3 and 4.

\section{Results}

\subsection{Required Simulations}

[22] Total (gas + aqueous) concentrations of 13 species for the two required simulations are shown in Figures 1-3.
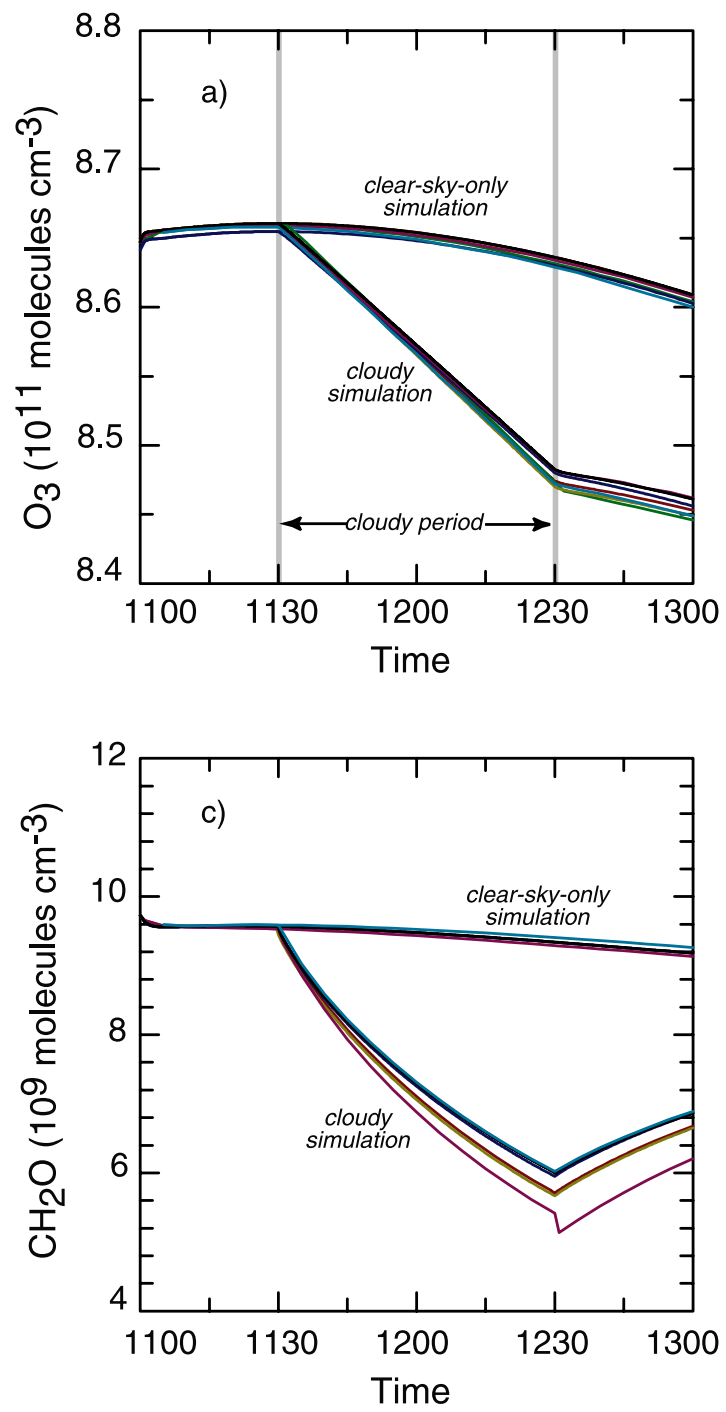

Figure 1. Total (gas + aqueous) concentration of function of time for the required simulations.
Note that the scaling of the y-axis in these figures is such that differences between models can easily be seen compared to the range of concentrations experienced during the integration and that the origin is not always zero. The average concentrations and standard deviation are computed at $\mathrm{t}=1200$, halfway through the integration, (Table 7) and at the end of the simulation (Table 8 ) for these same species.

[23] The clear-sky-only simulation is a reference case, for which we expect good agreement, but can be used to evaluate the effect of aqueous chemistry on tropospheric oxidants. The different models agree well $(<1 \%$ variation for most species, Tables 7 and 8 ) for this simulation, thus variations between models for the simulations with aqueous chemistry can be attributed to the aqueous chemistry or the methods employed for determining transfer between gas and aqueous phases.

[24] For the cloudy simulation, disagreement between simulations is greater than the clear-sky-only simulation (Figures 1-3). During the cloudy period of the simulation, most species differ from the mean value of the simulations by $<6 \%$ (Table 7 ), yet $\mathrm{HCOOH}, \mathrm{NO}_{3}$, and $\mathrm{HO}_{2}$ differ by $10-20 \%$ of its mean value. Hydroxyl and peroxy radicals
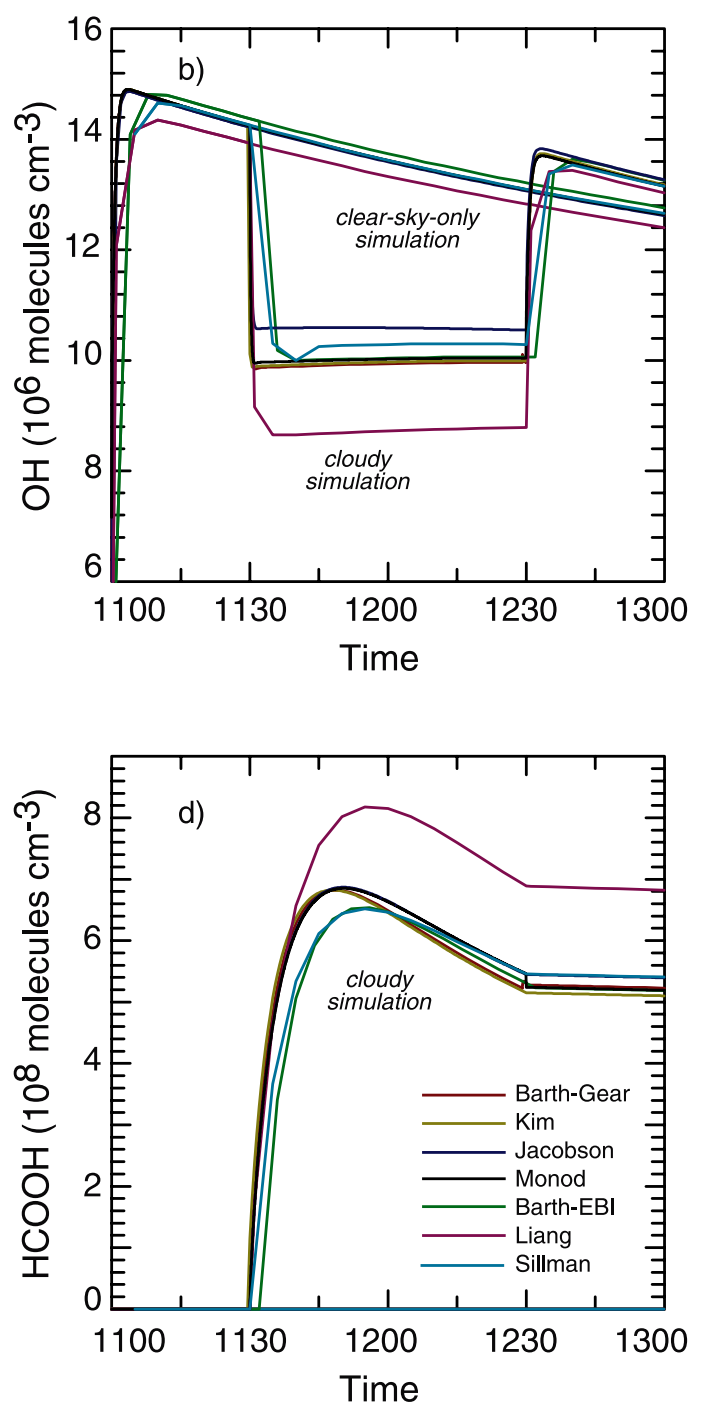

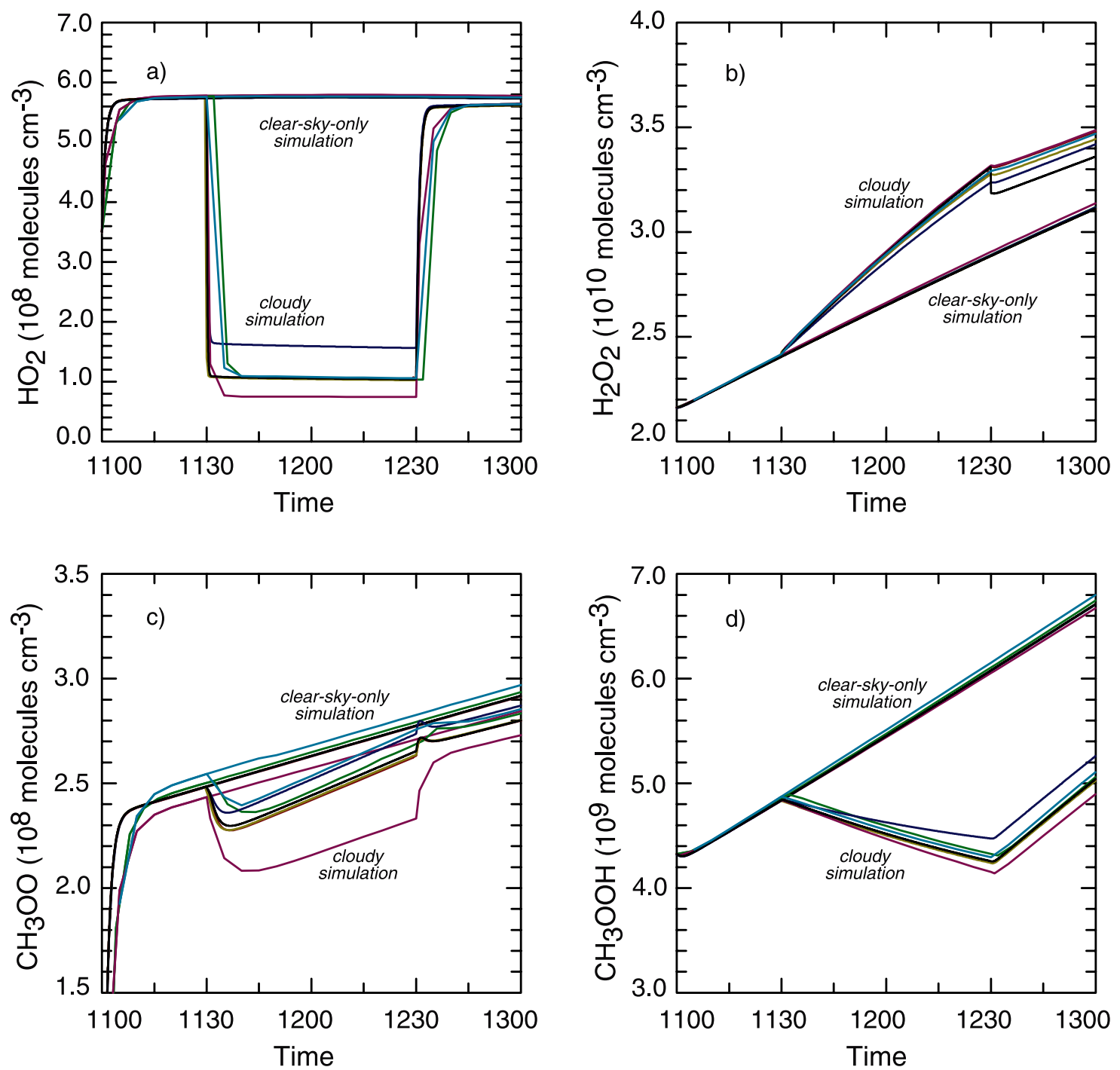

Figure 2. Total (gas + aqueous) concentration of (a) $\mathrm{HO}_{2}$, (b) $\mathrm{H}_{2} \mathrm{O}_{2}$, (c) $\mathrm{CH}_{3} \mathrm{OO}$, and (d) $\mathrm{CH}_{3} \mathrm{OOH}$ as a function of time for the required simulations. Color legend is shown in Figure 1.

$\left(\mathrm{OH}, \mathrm{HO}_{2}, \mathrm{CH}_{3} \mathrm{OO}\right)$ display larger deviations from the mean during the cloudy period than afterwards because these short-lived radicals are quickly controlled by the gasphase chemistry. Other species $\left(\mathrm{H}_{2} \mathrm{O}_{2}, \mathrm{CH}_{3} \mathrm{OOH}, \mathrm{NO}_{2}\right.$, $\mathrm{HNO}_{3}$, and $\mathrm{CH}_{2} \mathrm{O}$ ) show greater deviations from the mean after the cloudy period rather than during the cloudy period. This is due to increased deviations when the cloud suddenly evaporates $\left(\mathrm{H}_{2} \mathrm{O}_{2}, \mathrm{CH}_{3} \mathrm{OOH}, \mathrm{HNO}_{3}, \mathrm{CH}_{2} \mathrm{O}\right) . \mathrm{NO}_{2}$ likely has greater deviations because of its rapid exchange with NO, gaining the large deviations that NO exhibited.

[25] It is of interest to examine the accuracy of the model representing gas and aqueous chemistry as a function of its prescribed time step. The Barth-EBI and Sillman models are both used for this evaluation. In the standard cloudy simulation, the Barth-EBI and Sillman models have time steps of 4 and $5 \mathrm{~min}$; values that are commonly used in regional scale chemistry transport models. Figure 4 shows total $\mathrm{CH}_{2} \mathrm{O}$ concentrations from simulations using time steps of $6 \mathrm{~s}, 1 \mathrm{~min}, 4 \mathrm{~min}, 5 \mathrm{~min}, 20 \mathrm{~min}$, and $30 \mathrm{~min}$. Results from the two Sillman simulations at $\Delta \mathrm{t}=5$ and $30 \mathrm{~min}$ are within $2 \%$ of each other at the end of the simulation. The Barth-EBI final concentrations for $\Delta t=6$, 60,240 , and $300 \mathrm{~s}$ are within $1 \%$ of each other, while for $\Delta \mathrm{t}=20$ and $30 \mathrm{~min}$ the concentrations are within $3 \%$ of the other Barth-EBI final concentrations. Although some deviation occurs for large time steps compared to the small time steps, the simulations at all prescribed time steps agree quite well for the conditions specified. We also discuss the accuracy of the gas-aqueous chemistry model as a function of time step for the optional intermittent cloud simulation in the next section.

\subsection{Optional Simulations}

[26] Results from the required simulations show that the seven chemical models reproduce predicted concentrations of several species with good agreement among the solvers. By keeping the degree of variability among model results in mind, we can now explore the effect on species concentration under different conditions. These simulations are termed optional simulations, of which 2 were performed. We describe each of the optional simulations and their results. 

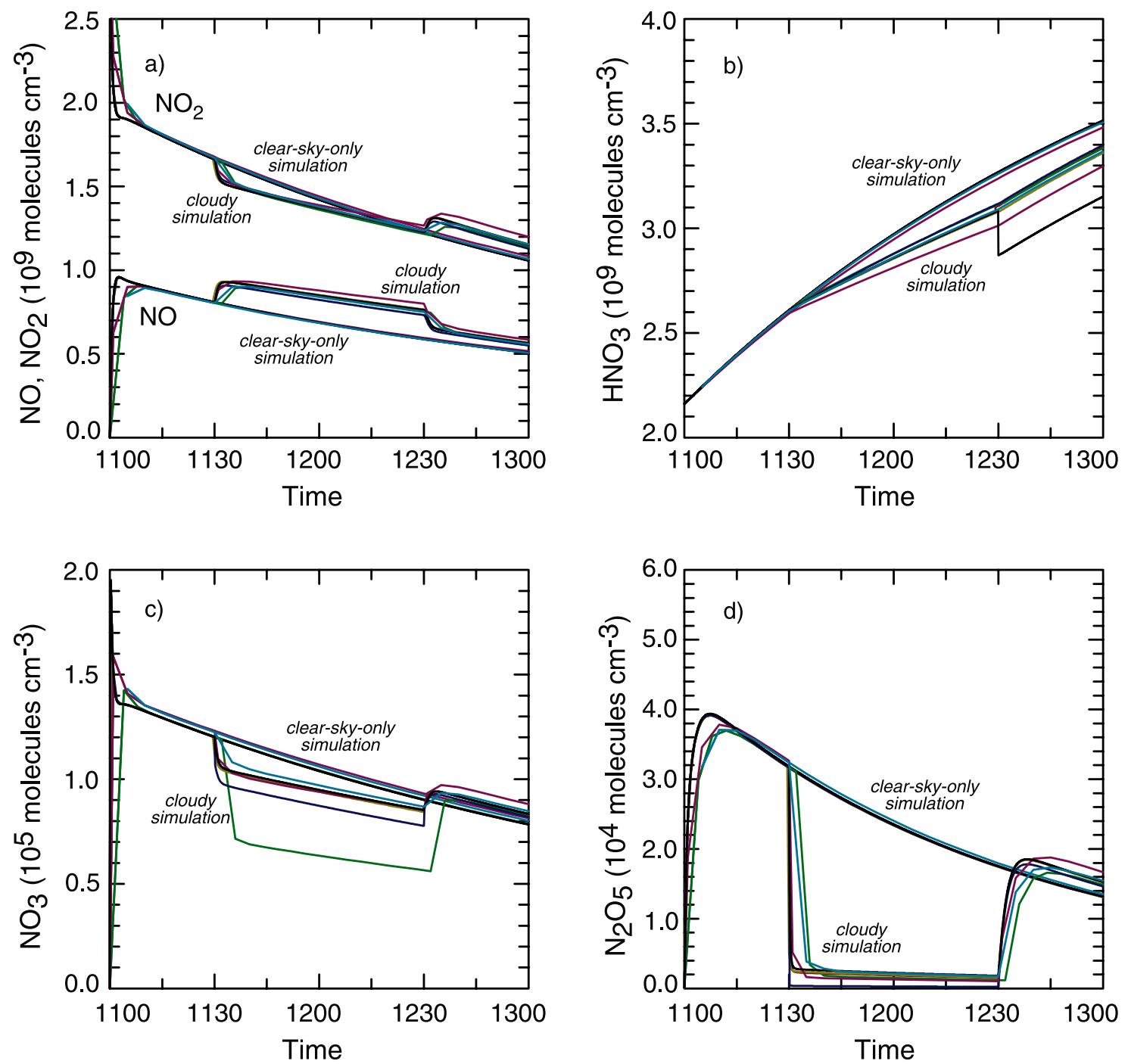

Figure 3. Total (gas + aqueous) concentration of (a) $\mathrm{NO}, \mathrm{NO}_{2}$, (b) $\mathrm{HNO}_{3}$, (c) $\mathrm{NO}_{3}$, and (d) $\mathrm{N}_{2} \mathrm{O}_{5}$ as a function of time for the required simulations. Color legend is shown in Figure 1.

\subsubsection{Intermittent Cloud}

[27] The first optional simulation, called the intermittent cloud simulation, is designed to determine the importance of how an air parcel is exposed to cloudy simulations. The intermittent cloud simulation attempts to imitate an air parcel moving in and out of a cloud, thus the simulation is more realistic than the required continuous cloud simulation. To compare the intermittent cloud simulation with

Table 7. Concentrations at Time $=1200^{\mathrm{a}}$

\begin{tabular}{lccc}
\hline Species & Clear Air $($ molec cm & & \\
& & Cloudy $\left(\mathrm{molec} \mathrm{cm}^{-3}\right)$ & $\begin{array}{c}\text { Difference Between Clear and } \\
\text { Cloudy }(\%)\end{array}$ \\
\hline $\mathrm{O}_{3}$ & $8.652( \pm 0.002) \times 10^{11}$ & $8.569( \pm 0.003) \times 10^{11}$ & $-0.96( \pm 0.04)$ \\
$\mathrm{OH}$ & $1.359( \pm 0.012) \times 10^{7}$ & $9.946( \pm 0.585) \times 10^{6}$ & $-26.83( \pm 3.83)$ \\
$\mathrm{CH}_{2} \mathrm{O}$ & $9.480( \pm 0.027) \times 10^{9}$ & $7.163( \pm 0.158) \times 10^{9}$ & $-24.44( \pm 1.50)$ \\
$\mathrm{HCOOH}_{\mathrm{HO}_{2}}$ & 0.000 & $6.613( \pm 0.793) \times 10^{8}$ & $\infty$ \\
$\mathrm{H}_{2} \mathrm{O}_{2}$ & $5.766( \pm 0.017) \times 10^{8}$ & $1.088( \pm 0.251) \times 10^{8}$ & $-81.12( \pm 4.39)$ \\
$\mathrm{CH}_{3} \mathrm{OO}$ & $2.656( \pm 0.008) \times 10^{10}$ & $2.885( \pm 0.017) \times 10^{10}$ & $8.65( \pm 0.60)$ \\
$\mathrm{CH}_{3} \mathrm{OOH}$ & $2.632( \pm 0.032) \times 10^{8}$ & $2.424( \pm 0.126) \times 10^{8}$ & $-7.93( \pm 3.86)$ \\
$\mathrm{NO}$ & $5.461( \pm 0.025) \times 10^{9}$ & $4.542( \pm 0.056) \times 10^{9}$ & $-16.84( \pm 0.96)$ \\
$\mathrm{NO}_{2}$ & $6.874( \pm 0.023) \times 10^{8}$ & $8.478( \pm 0.168) \times 10^{8}$ & $23.33( \pm 2.13)$ \\
$\mathrm{HNO}_{3}$ & $1.426( \pm 0.007) \times 10^{9}$ & $1.375( \pm 0.008) \times 10^{9}$ & $-3.59( \pm 0.39)$ \\
$\mathrm{NO}_{3}$ & $2.966( \pm 0.009) \times 10^{9}$ & $2.857( \pm 0.022) \times 10^{9}$ & $-3.68( \pm 0.52)$ \\
$\mathrm{N}_{2} \mathrm{O}_{5}$ & $1.047( \pm 0.013) \times 10^{5}$ & $8.931( \pm 1.197) \times 10^{4}$ & $-14.75( \pm 11.25)$ \\
\hline
\end{tabular}

${ }^{\mathrm{a}}$ Values are averages of the seven models. Uncertainties are standard deviations of the seven models. 
Table 8. Concentrations at Time $=1300^{\mathrm{a}}$

\begin{tabular}{lccc}
\hline Species & $\begin{array}{c}\text { Clear Air } \\
(\text { molec cm }\end{array}$ & $\begin{array}{c}\text { Cloudy } \\
\left(\text { molec cm }^{-3}\right)\end{array}$ & $\begin{array}{c}\text { Difference } \\
\text { Between Clear } \\
\text { and Cloudy }(\%)\end{array}$ \\
\hline $\mathrm{O}_{3}$ & $8.606( \pm 0.004) \times 10^{11}$ & $8.454( \pm 0.006) \times 10^{11}$ & $-1.77( \pm 0.07)$ \\
$\mathrm{OH}$ & $1.262( \pm 0.011) \times 10^{7}$ & $1.317( \pm 0.008) \times 10^{7}$ & $4.35( \pm 0.53)$ \\
$\mathrm{CH}_{2} \mathrm{O}$ & $9.189( \pm 0.038) \times 10^{10}$ & $6.681( \pm 0.238) \times 10^{9}$ & $-27.29( \pm 2.40)$ \\
$\mathrm{HCOOH}$ & 0.000 & $5.521( \pm 0.592) \times 10^{8}$ & $\infty$ \\
$\mathrm{HO}_{2}$ & $5.748( \pm 0.018) \times 10^{8}$ & $5.634( \pm 0.011) \times 10^{8}$ & $-1.99( \pm 0.24)$ \\
$\mathrm{H}_{2} \mathrm{O}_{2}$ & $3.123( \pm 0.014) \times 10^{10}$ & $3.444( \pm 0.043) \times 10^{10}$ & $10.28( \pm 1.20)$ \\
$\mathrm{CH}_{3} \mathrm{OO}$ & $2.917( \pm 0.037) \times 10^{8}$ & $2.813( \pm 0.046) \times 10^{8}$ & $-3.56( \pm 0.89)$ \\
$\mathrm{CH}_{3} \mathrm{OOH}$ & $6.723( \pm 0.040) \times 10^{9}$ & $5.061( \pm 0.110) \times 10^{9}$ & $-24.73( \pm 1.52)$ \\
$\mathrm{NO}^{\mathrm{NO}}$ & $5.086( \pm 0.033) \times 10^{8}$ & $5.638( \pm 0.105) \times 10^{8}$ & $10.86( \pm 1.49)$ \\
$\mathrm{HNO}_{3}$ & $1.063( \pm 0.009) \times 10^{9}$ & $1.154( \pm 0.022) \times 10^{9}$ & $8.58( \pm 1.35)$ \\
$\mathrm{NO}_{3}$ & $3.508( \pm 0.012) \times 10^{9}$ & $3.335( \pm 0.088) \times 10^{9}$ & $-4.93( \pm 2.48)$ \\
$\mathrm{N}_{2} \mathrm{O}_{5}$ & $7.915( \pm 0.119) \times 10^{4}$ & $8.393( \pm 0.202) \times 10^{4}$ & $6.04( \pm 1.24)$ \\
\hline${ }^{a}$ Values are averages of the seven models. Uncertainties are standard & $1.333( \pm 0.030) \times 10^{4}$ & $1.535( \pm 0.065) \times 10^{4}$ & $15.17( \pm 2.78)$ \\
deviations of the seven models. $^{4}$ &
\end{tabular}

the required cloud simulation, the required cloud simulation was extended for another 50 minutes so that each simulation had the same amount of time of clear air and cloudy air exposures.
[28] This simulation offers the opportunity to further examine the sensitivity of the model results to the time step prescribed. Four models, Barth-Gear, Barth-EBI, Kim, and Sillman, performed the intermittent cloud simulation. Figure 5 shows the total concentration of $\mathrm{CH}_{2} \mathrm{O}$ for the Barth-Gear and Kim models, which both have variable time steps, the Barth-EBI model at $\Delta \mathrm{t}=5,4,1 \mathrm{~min}$, and $6 \mathrm{~s}$, and the Sillman model at $\Delta t=5$ and $1 \mathrm{~min}$. The results for all time steps tested by the Sillman and Barth-EBI models except for the Barth-EBI at $\Delta \mathrm{t}=4 \mathrm{~min}$, agree very well. The two traces for the Barth-EBI $\Delta \mathrm{t}=4 \mathrm{~min}$ illustrate the importance of having the chemistry time step be a multiple of the cloud time step so that the chemistry time step corresponds to the appearance and disappearance of cloud. The top trace shows results of a simulation that resolved 2 time points during the cloudy interval and 3 time points during the $10 \mathrm{~min}$ clear air intervals, while the bottom trace reflects results of a simulation that resolved 3 time points during the cloudy interval and 2 time points during the 10 min clear air interval. Because neither trace temporally resolves the cloudy-clear air intervals equally, the model results deviate from the more accurate solutions by $5-6 \%$. Based on these

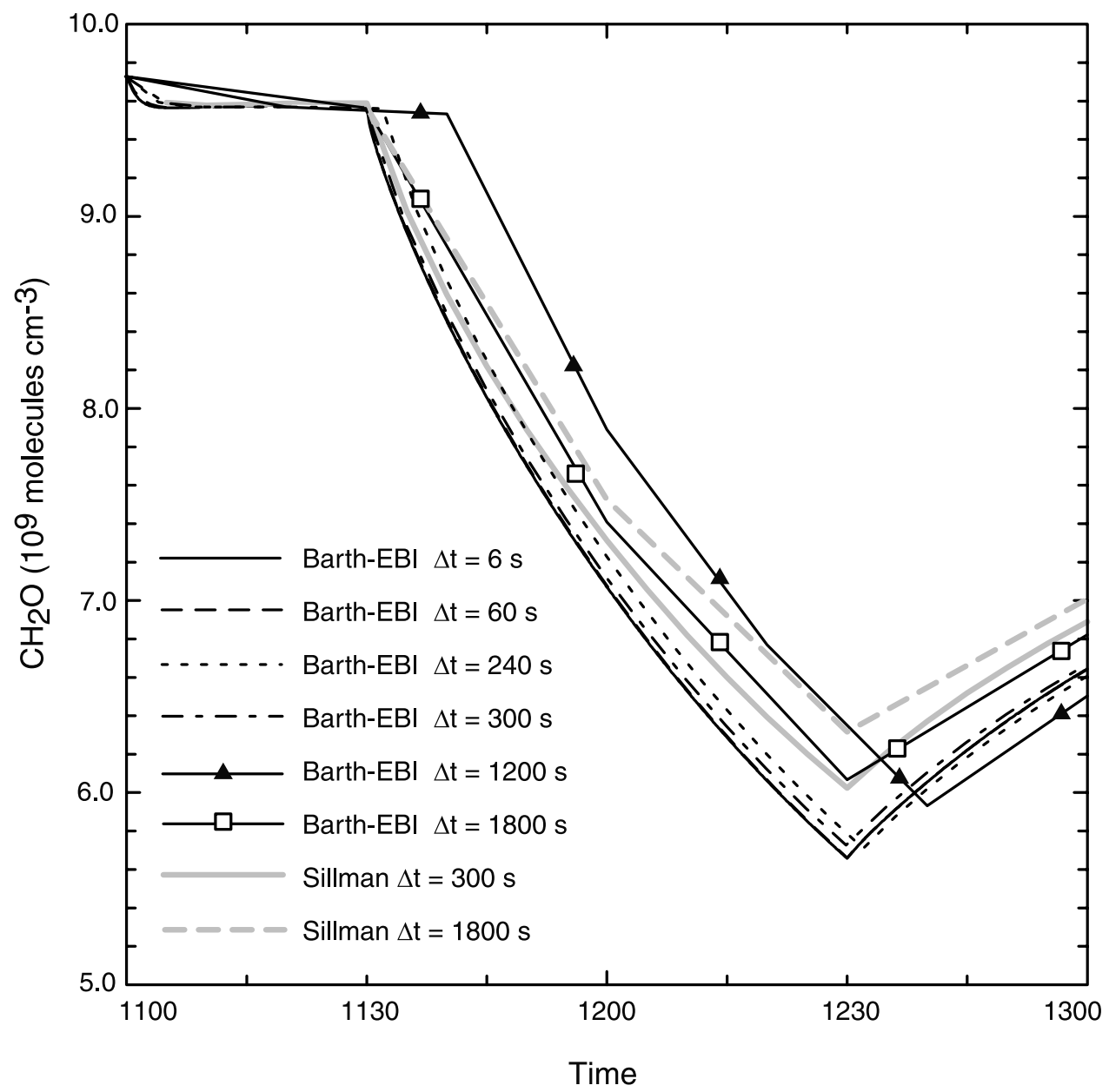

Figure 4. Total concentration of $\mathrm{CH}_{2} \mathrm{O}$ as a function of time for the required cloudy simulation using the Barth-EBI at $\Delta \mathrm{t}=6 \mathrm{~s}$ (solid black), Barth-EBI at $\Delta \mathrm{t}=60 \mathrm{~s}$ (dashed black), Barth-EBI at $\Delta \mathrm{t}=240 \mathrm{~s}$ (dotted black), Barth-EBI at $\Delta \mathrm{t}=300 \mathrm{~s}$ (dash-dotted black), Barth-EBI at $\Delta \mathrm{t}=1200 \mathrm{~s}$ (solid black with triangles), Barth-EBI at $\Delta \mathrm{t}=1800 \mathrm{~s}$ (solid black with squares), Sillman at $\Delta \mathrm{t}=300 \mathrm{~s}$ (solid gray) and Sillman at $\Delta \mathrm{t}=1800 \mathrm{~s}$ (dashed gray) models. 


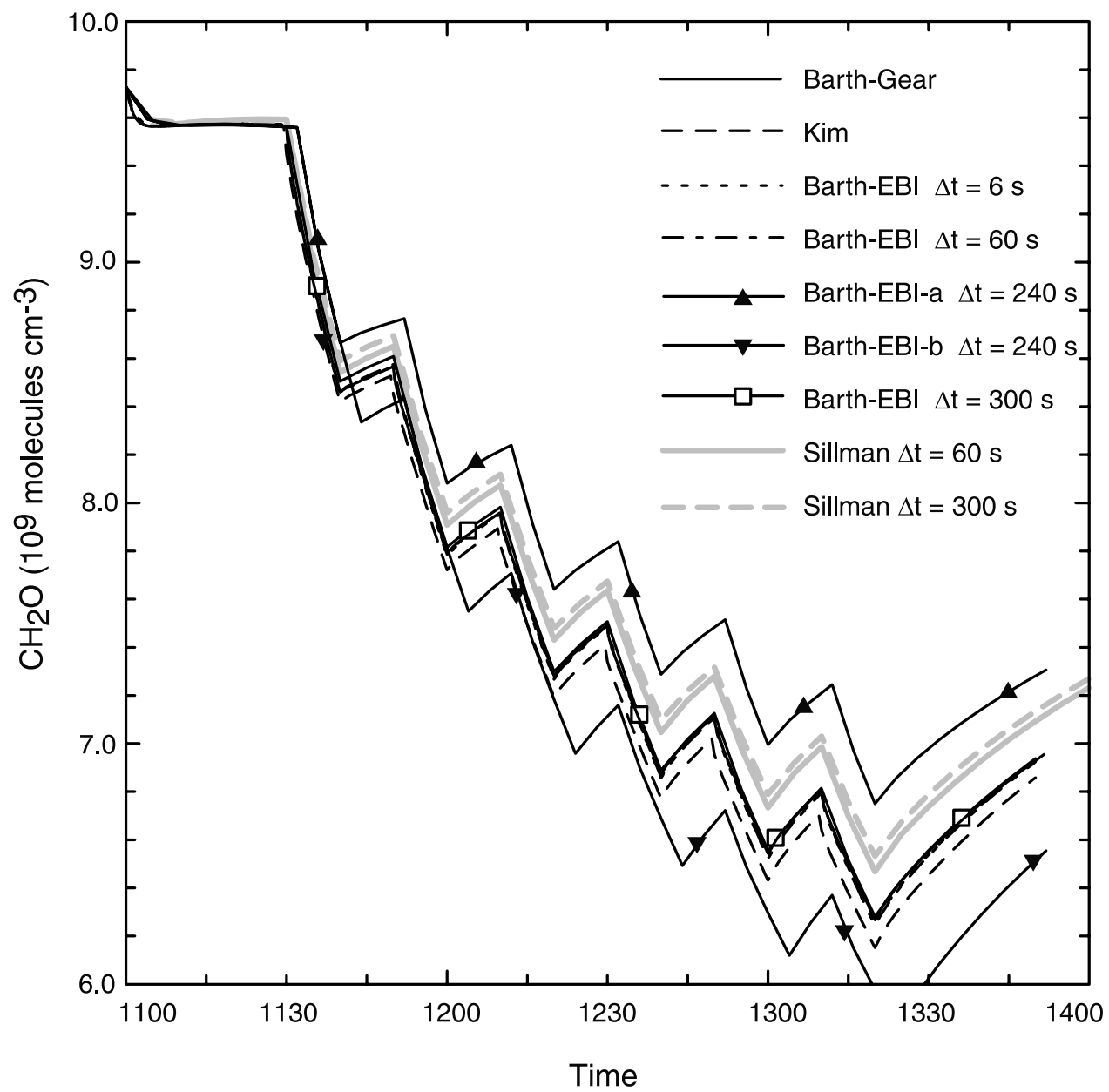

Figure 5. Total concentration of $\mathrm{CH}_{2} \mathrm{O}$ as a function of time for the intermittent cloudy simulation using the Barth-Gear solver (solid black), Kim (dashed black), Barth-EBI at $\Delta \mathrm{t}=6 \mathrm{~s}$ (dotted black), Barth-EBI at $\Delta \mathrm{t}=60 \mathrm{~s}$ (dash-dotted black), Barth-EBI-a at $\Delta \mathrm{t}=240 \mathrm{~s}$ in which 2 time points are resolved during the cloudy period (black with triangles), Barth-EBI-b at $\Delta \mathrm{t}=240 \mathrm{~s}$ in which 3 time points are resolved during the cloudy period (black with upside-down triangles), Barth-EBI at $\Delta \mathrm{t}=300 \mathrm{~s}$ (black with squares), Sillman at $\Delta \mathrm{t}=60 \mathrm{~s}$ (solid gray) and Sillman at $\Delta \mathrm{t}=300 \mathrm{~s}$ (dashed gray).

results, it is more important to select a chemistry time step that is a multiple of the cloud time step than to have high temporal resolution (i.e., a small time step). For investigations that employ a cloud-scale numerical model of chemistry and cloud physics, the chemistry time step can be set to a multiple $f$ of the cloud physics time step (i.e., $\Delta t_{\text {chem }}=$ $f \Delta t_{\text {cloud }}$ ). In many cloud chemistry models, $f=1$.

[29] To examine differences between the intermittent cloud simulation and the continuous cloud simulation, the results from the Barth-EBI at $\Delta t=4$ min are excluded so that we compare only the solvers whose time step corresponds to the appearance and disappearance of cloud. Figures 6-8 show the total concentration of 13 species as a function of time for the intermittent cloud simulation and the continuous cloud simulation. By the end of the simulation, $\mathrm{O}_{3}, \mathrm{OH}, \mathrm{HO}_{2}, \mathrm{CH}_{3} \mathrm{OO}, \mathrm{NO}, \mathrm{NO}_{2}, \mathrm{HNO}_{3}, \mathrm{NO}_{3}$, and $\mathrm{N}_{2} \mathrm{O}_{5}$ concentrations are nearly the same for both cloudy simulations. On the other hand, $\mathrm{CH}_{2} \mathrm{O}, \mathrm{HCOOH}, \mathrm{H}_{2} \mathrm{O}_{2}$, and $\mathrm{CH}_{3} \mathrm{OOH}$ concentrations at the end of the simulation are much different for the two cloudy simulations. In all of the simulations, $\mathrm{NO}_{x}$ is depleted substantially $\left(\mathrm{NO}_{x}\right.$ concentra- tion at the end of the simulation is about half that initially) so one might conclude that exposing the air parcel to cloud during the late part of the simulation when $\mathrm{NO}_{x}$ concentrations are lower would create the difference observed in $\mathrm{CH}_{2} \mathrm{O}, \mathrm{HCOOH}$ and peroxide concentrations. By performing other continuous cloud simulations in which the cloud occurs at a later time in the integration, we can determine how much the $\mathrm{NO}_{x}$ levels affect $\mathrm{CH}_{2} \mathrm{O}, \mathrm{HCOOH}$, and the peroxides. Formaldehyde results from two simulations with cloud appearing later in the integration (Figure 9) show that $\mathrm{CH}_{2} \mathrm{O}$ is not affected by the $\mathrm{NO}_{x}$ level, because the depletion of total $\mathrm{CH}_{2} \mathrm{O}$ during cloud exposure is the same for all of the continuous cloud simulations (compare $\mathrm{CH}_{2} \mathrm{O}$ concentrations from Barth-Gear $\mathrm{t}=1230$ of the standard simulation to $\mathrm{t}=1320$ of the Barth-Gear "late cloud" simulation; compare $\mathrm{CH}_{2} \mathrm{O}$ concentrations from Sillman $\mathrm{t}=1230$ of the standard simulation to Sillman $\mathrm{t}=1300$ of the "late cloud" simulation). For the "late cloud" simulations total formaldehyde concentration at $\mathrm{t}=1350$ is smaller than that from the standard simulation because the late cloud simulation has had less time available to return 

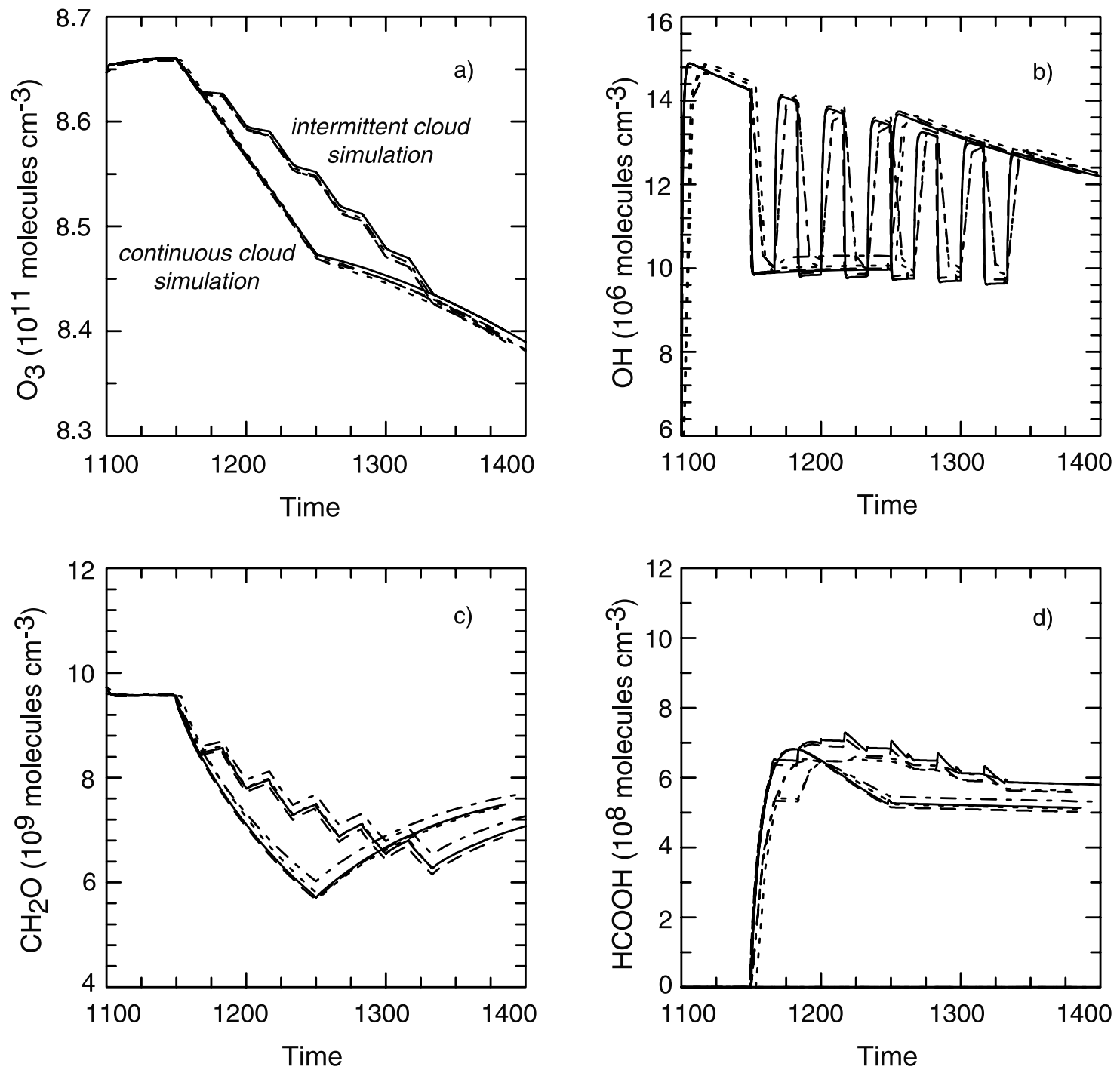

Figure 6. Total concentration of (a) $\mathrm{O}_{3}$, (b) $\mathrm{OH}$, (c) $\mathrm{CH}_{2} \mathrm{O}$, and (d) $\mathrm{HCOOH}$ as a function of time for the intermittent cloudy and continuous cloud simulations for the Barth-Gear (solid), Kim (dashed), BarthEBI (dotted) at $\Delta \mathrm{t}=5 \mathrm{~min}$, and Sillman (dash-dotted) models

$\mathrm{CH}_{2} \mathrm{O}$ concentrations back to its steady state. Formic acid concentrations at the end of the "late cloud" simulations are the same as those from the standard continuous cloud simulation, and all continuous cloud simulation $\mathrm{s}$ result in smaller $\mathrm{HCOOH}$ concentrations than those from the intermittent cloud simulation. $\mathrm{NO}_{x}$ levels do not contribute to the increase in $\mathrm{HCOOH}$ when comparing the continuous cloud simulation and intermittent cloud simulation results. This is further verified by examining $\mathrm{CH}_{2} \mathrm{O}$ and $\mathrm{HCOOH}$ results from simulations in which $\mathrm{NO}_{x}$ concentrations are held constant at 100 pptv. At the end of the simulation $\mathrm{CH}_{2} \mathrm{O}$ and $\mathrm{HCOOH}$ differ by $5 \%$ and $17 \%$ (Figure 10 ) between the continuous cloud simulation and the intermittent cloud simulation.

[30] By analyzing the $\mathrm{CH}_{2} \mathrm{O}$ production and destruction terms during the clear-sky and cloudy intervals of the intermittent cloud simulation and during the cloud period and 50 min of clear sky immediately following cloud of the continuous cloud simulation, an explanation emerges of why final $\mathrm{CH}_{2} \mathrm{O}$ concentrations differ between these two simu- lations. During the 510 -min clear-sky intervals of the intermittent cloud simulation and during the $50 \mathrm{~min}$ of clear air following cloud of the continuous cloud simulation, the net production of $\mathrm{CH}_{2} \mathrm{O}$ is positive and is larger for the continuous cloud simulation for these time periods because there is less $\mathrm{CH}_{2} \mathrm{O}$ destruction (the $\mathrm{CH}_{2} \mathrm{O}$ production rate is nearly the same for both simulations). During cloud exposure, for both simulations the net production of $\mathrm{CH}_{2} \mathrm{O}$ is negative as a result of the aqueous-phase oxidation of $\mathrm{CH}_{2} \mathrm{O}$, whose rate is 2.5 times faster than the gas-phase oxidation of $\mathrm{CH}_{2} \mathrm{O}$ by $\mathrm{OH}$. The destruction of $\mathrm{CH}_{2} \mathrm{O}$ during these time periods is greater for the intermittent cloud simulation than for the continuous cloud simulation because there is more $\mathrm{CH}_{2} \mathrm{O}$ available to react. Thus, the clear-sky intervals produce $\mathrm{CH}_{2} \mathrm{O}$ allowing for greater aqueous-phase destruction of $\mathrm{CH}_{2} \mathrm{O}$ in the intermittent cloud simulation resulting in a smaller $\mathrm{CH}_{2} \mathrm{O}$ concentration at the end of the simulation compared to that in the continuous cloud simulation.

[31] During cloud exposure, total $\mathrm{HCOOH}$ is in steadystate equilibrium with its aqueous-phase production and 

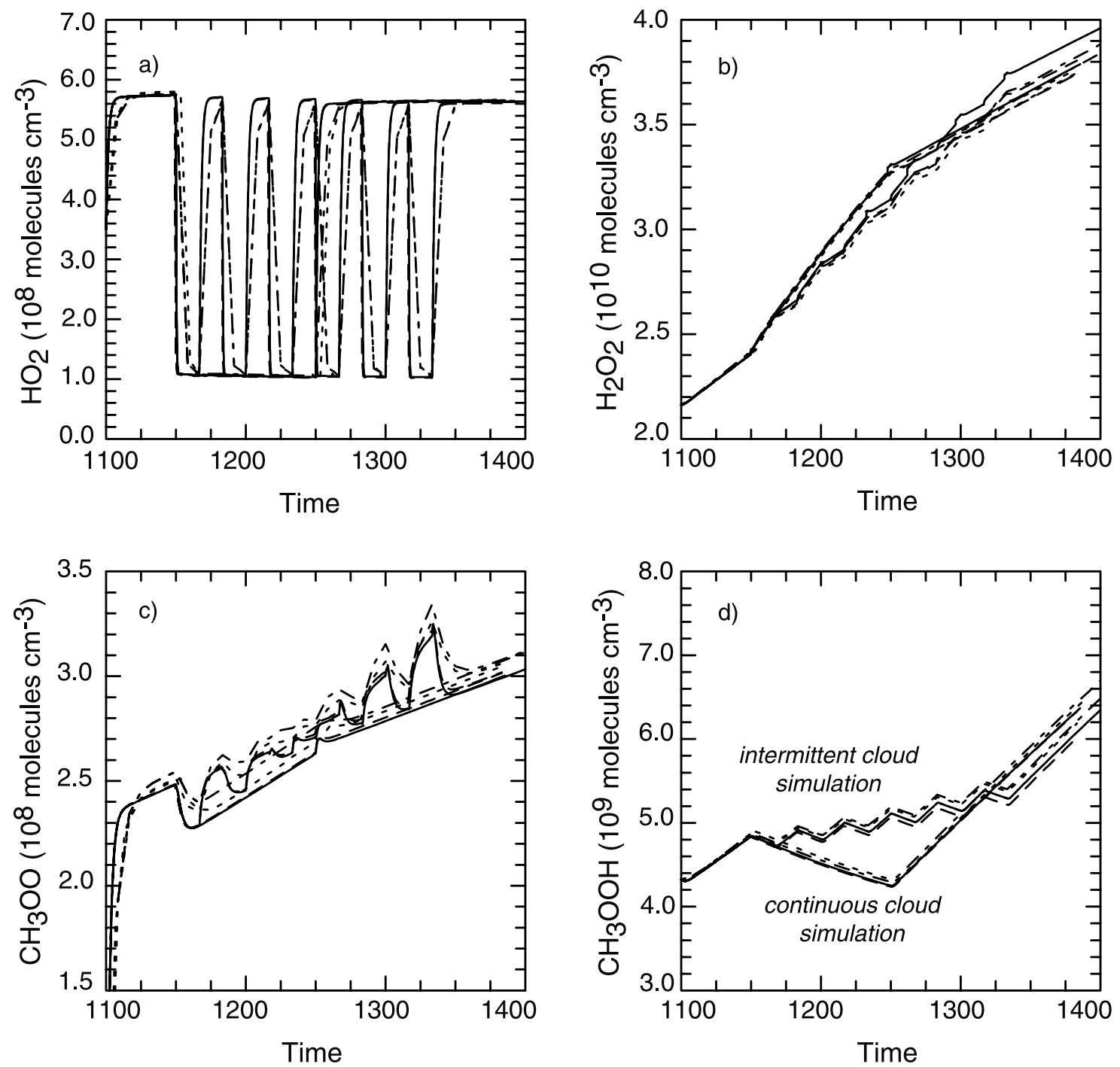

Figure 7. Total concentration of (a) $\mathrm{HO}_{2}$, (b) $\mathrm{H}_{2} \mathrm{O}_{2}$, (c) $\mathrm{CH}_{3} \mathrm{OO}$, and (d) $\mathrm{CH}_{3} \mathrm{OOH}$ as a function of time for the intermittent cloudy and continuous cloud simulations for the Barth-Gear (solid), Kim (dashed), Barth-EBI (dotted) at $\Delta \mathrm{t}=5 \mathrm{~min}$, and Sillman (dash-dotted) models.

destruction [Chameides, 1984]. Consequently HCOOH concentrations are directly linked to $\mathrm{CH}_{2} \mathrm{O}$ concentrations because reaction (A3) is the only source of $\mathrm{HCOOH}$. At the end of the last cloudy interval in the intermittent cloud simulation, total $\mathrm{CH}_{2} \mathrm{O}$ is greater than total $\mathrm{CH}_{2} \mathrm{O}$ at the end of the cloud period in the continuous cloud simulation. As a result, the final $\mathrm{HCOOH}$ concentration is also greater for the intermittent cloud simulation than that for the continuous cloud simulation.

[32] In summary, the intermittent cloud simulation reveals that the manner an air parcel is exposed to cloud can be important to the concentrations of some species. For the conditions specified in this study, $\mathrm{CH}_{2} \mathrm{O}$ and $\mathrm{HCOOH}$ concentrations are altered. Although representing cloud exposures intermittently is more realistic than one continuous cloud exposure, it is still not completely realistic. A more realistic simulation would represent additional processes such as cloud drop activation and prediction of $\mathrm{pH}$. Because much of the aqueous chemistry depends on the acidity of the drops (reactions A4-A6, A9-A10, A12, $\mathrm{A} 15-\mathrm{A} 25)$, the variation of $\mathrm{pH}$ during any one cloud period and the variation of $\mathrm{pH}$ among cloud exposures could result in substantially different concentrations for several species. The effect of predicting $\mathrm{pH}$ during one cloud exposure is presented next.

\subsubsection{Variable $\mathrm{pH}$}

[33] The second optional simulation is aimed at determining the importance of prescribing the $\mathrm{pH}$ of the cloud water to calculating the $\mathrm{pH}$ so that $\mathrm{pH}$ can vary according to the aqueous chemistry. Results from the variable $\mathrm{pH}$ simulation showed that the $\mathrm{pH}$ did not vary much, but was calculated to be between 3.92 and 3.94 (Figure 11), which is much lower than that prescribed in the required simulation where $\mathrm{pH}=$ 5. The low $\mathrm{pH}$ values occur because the variable $\mathrm{pH}$ simulation did not represent cations, such as $\mathrm{Na}^{+}, \mathrm{NH}_{4}^{+}$, or $\mathrm{Ca}^{2+}$, that are present in the cloud condensation nuclei before cloud drop activation. The lower $\mathrm{pH}$ has a large impact on the total concentrations of $\mathrm{O}_{3}, \mathrm{CH}_{2} \mathrm{O}, \mathrm{HCOOH}$, and $\mathrm{H}_{2} \mathrm{O}_{2}$ (Figure 12) because the relative amounts of $\mathrm{HO}_{2}$ and $\mathrm{HCOOH}$ and their anions in the aqueous solution are highly $\mathrm{pH}$ dependent. At lower $\mathrm{pH}$, there is less $\mathrm{O}_{2}^{-}$in the 

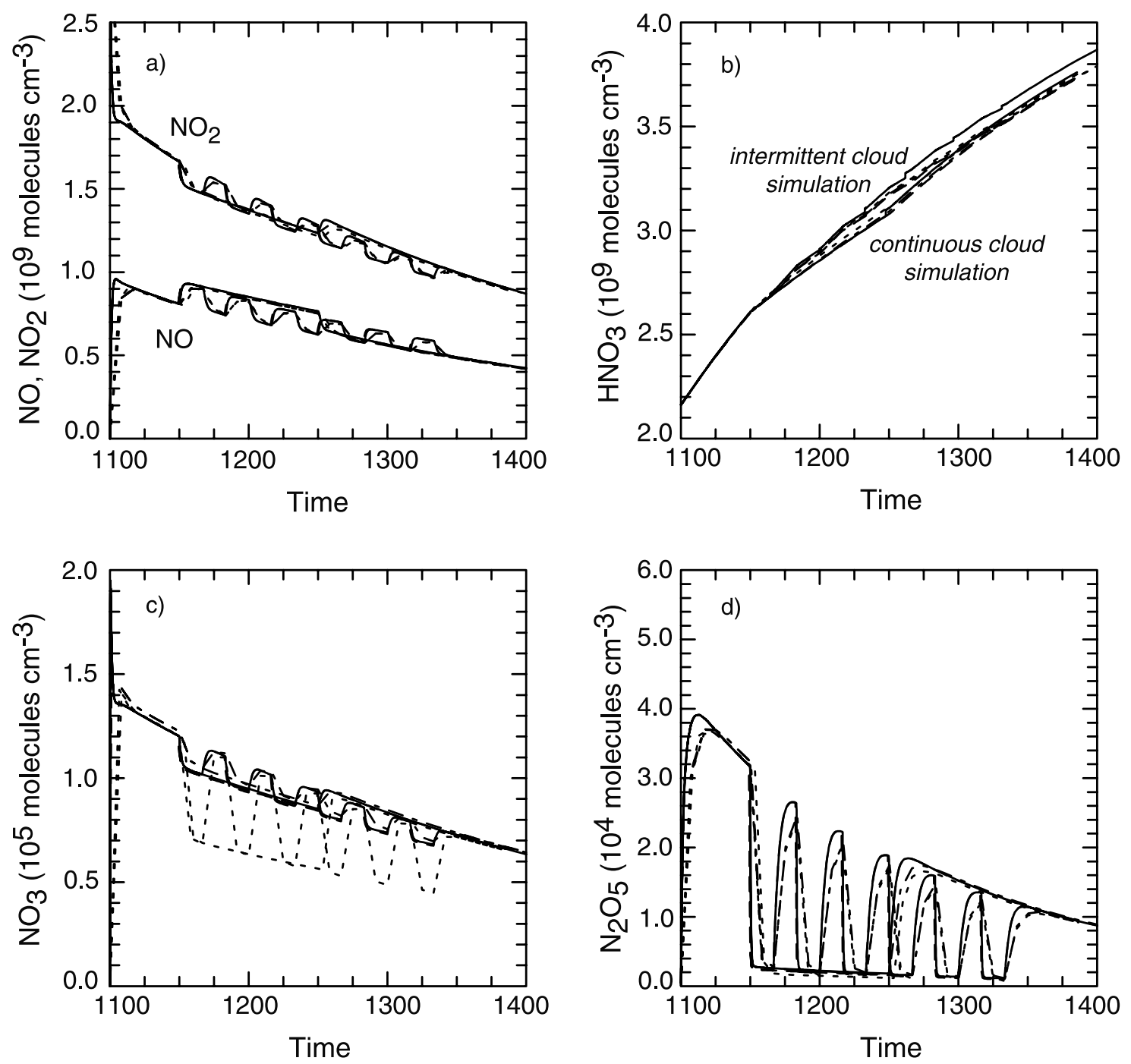

Figure 8. Total concentration of (a) $\mathrm{NO}, \mathrm{NO}_{2}$, (b) $\mathrm{HNO}_{3}$, (c) $\mathrm{NO}_{3}$, and (d) $\mathrm{N}_{2} \mathrm{O}_{5}$ as a function of time for the intermittent cloudy and continuous cloud simulations for the Barth-Gear (solid), Kim (dashed), Barth-EBI (dotted) at $\Delta \mathrm{t}=5 \mathrm{~min}$, and Sillman (dash-dotted) models.

cloud water compared to $\mathrm{HO}_{2}$ and thus reactions involving $\mathrm{O}_{2}^{-}$(A9 and A12 in particular) do not proceed as quickly as they do at higher $\mathrm{pH}$. As a result, there is less $\mathrm{O}_{3}$ depletion, and more $\mathrm{H}_{2} \mathrm{O}_{2}$ production. At lower $\mathrm{pH}$ there is also less $\mathrm{HCOO}^{-}$in the cloud water relative to $\mathrm{HCOOH}$. Consequently reactions involving $\mathrm{HCOO}^{-}$(A5) do not proceed as quickly as they do at higher $\mathrm{pH}$. Because loss of $\mathrm{HCOOH}$ is primarily through reaction of $\mathrm{HCOO}^{-}$and $\mathrm{OH}, \mathrm{HCOOH}$ destruction is negligible and therefore more $\mathrm{HCOOH}$ is produced at low $\mathrm{pH}$.

\section{Discussion}

[34] The simulations performed for the cloud chemistry intercomparison allow us to examine cloud chemistry in detail as a group of results because good agreement among the models was found for many of the predicted species. We examine the aqueous to gas phase concentration ratios during the cloudy period of the simulation to compare with what is expected from Henry's law equilibrium. We show the effect of aqueous-phase diffusion limitation, the effect of aqueous chemistry on the total concentration of the species, and discuss future directions of cloud chemistry modeling intercomparisons.

\subsection{Aqueous to Gas Phase Concentration Ratios During Cloud}

[35] In this section we show whether the participating models, which have been used in previous cloud chemistry studies, generally agree on the aqueous to gas phase concentration ratio and how this modeled phase ratio compares to Henry's law equilbrium. Many of the numerical models used for the simulations performed here represent the transfer of species between gas and aqueous phases as mass transport limited by diffusion in the gas phase and across the drop interface. Some models partition a few species by Henry's law equilibrium (section 2.2). The actual ratio of the aqueous concentration of a species to its gas-phase concentration can be compared to the Henry's law equilibrium phase ratio, which is defined as the product of the Henry's law constant, universal gas constant, temperature and liquid water content [Lelieveld and Crutzen, 1991]. 

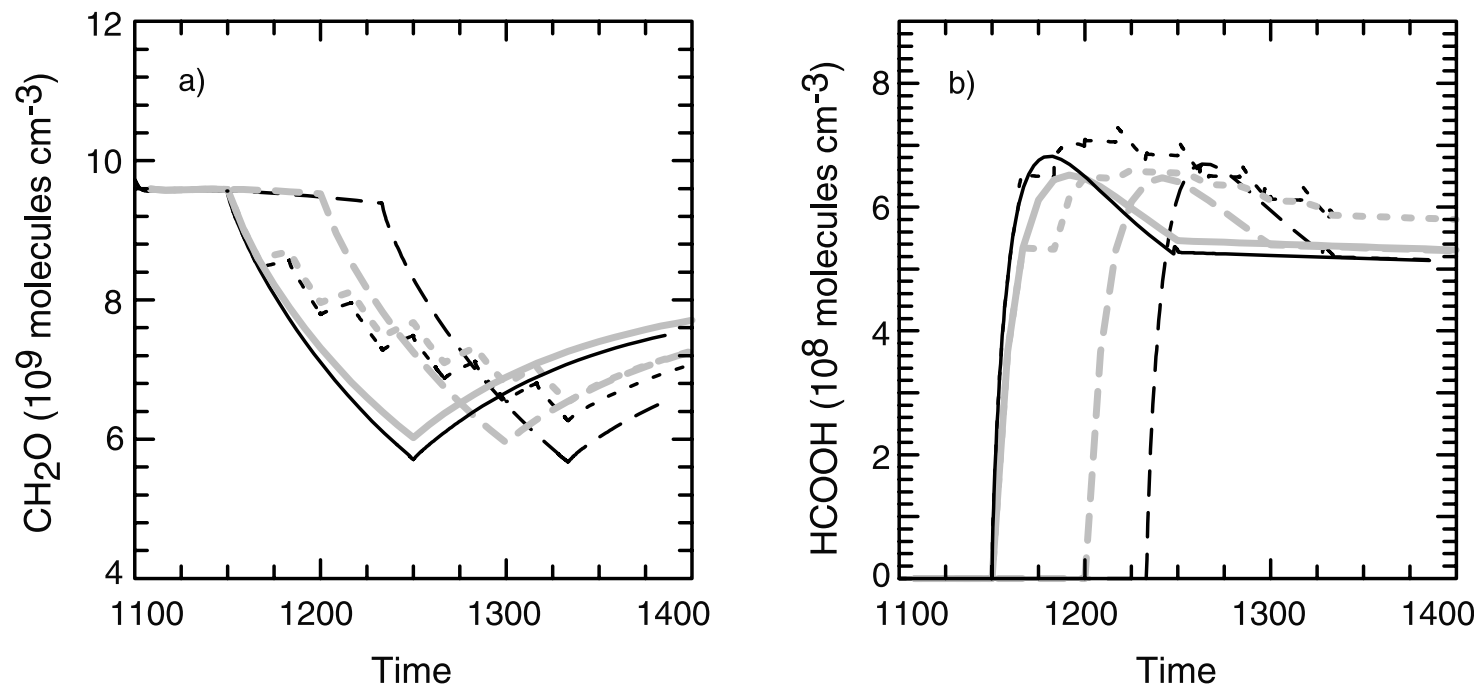

Figure 9. Total concentration of (a) $\mathrm{CH}_{2} \mathrm{O}$ and (b) $\mathrm{HCOOH}$ as a function of time for the standard continuous cloud simulation (solid lines; black is the Barth-Gear model, gray the Sillman model), for the intermittent cloud simulation (dotted lines; black is the Barth-Gear model, gray the Sillman model), for the "late cloud" continuous cloud where cloud is from $t=1200$ to $t=1300$ (gray dashed line, Sillman model), and for the "late cloud" continuous cloud where cloud is from $t=1220$ to $t=1320$ (black dashed line, Barth-Gear model).

[36] The actual ratios reported in Table 9 are the means and standard deviations of the 7 numerical models that integrated the standard cloudy simulation. The equilibrium phase ratio is computed from the known quantities appropriate for the time of comparison (one-half hour after the onset of cloud). The modeled phase ratios agree within $1 \%$ for $\mathrm{CH}_{2} \mathrm{O}, \mathrm{H}_{2} \mathrm{O}_{2}$, $\mathrm{CH}_{3} \mathrm{OO}, \mathrm{CH}_{3} \mathrm{OOH}, \mathrm{NO}$, and $\mathrm{NO}_{2}$, and agree within $\sim 20 \%$ for $\mathrm{O}_{3}, \mathrm{OH}, \mathrm{HCOOH}$, and $\mathrm{HO}_{2}$. The modeled phase ratios for $\mathrm{HNO}_{3}$ and $\mathrm{NO}_{3}$ display a large variability. Most of the variability for $\mathrm{HNO}_{3}$ arises from the prediction of the gasphase concentration and is not from the prediction of the aqueous-phase concentration. The Sillman model predicts the gas-phase $\mathrm{HNO}_{3}$ concentration to be 3 or so orders of magnitude smaller than the other models. However, this should have very little effect on gas-phase chemistry because $\mathrm{HNO}_{3}(\mathrm{~g})$ is extremely small during cloud. For $\mathrm{NO}_{3}$ most of the variability comes from the prediction of the aqueousphase concentration. The Barth-EBI model predicts that $\mathrm{NO}_{3}$ is in Henry's law equilbrium while the other models do not and this contributes significantly to the large variability of the modeled $\mathrm{NO}_{3}$ phase ratio. We find that the ratio of aqueous to gas-phase concentrations after half an hour in cloud are in Henry's law equilibrium for most species. Species that clearly are not in equilibrium are $\mathrm{OH}, \mathrm{HO}_{2}, \mathrm{HNO}_{3}$, and $\mathrm{NO}_{3}$.

[37] The ratios listed in Table 9 could be compared with those determined from field measurements [e.g., Munger et
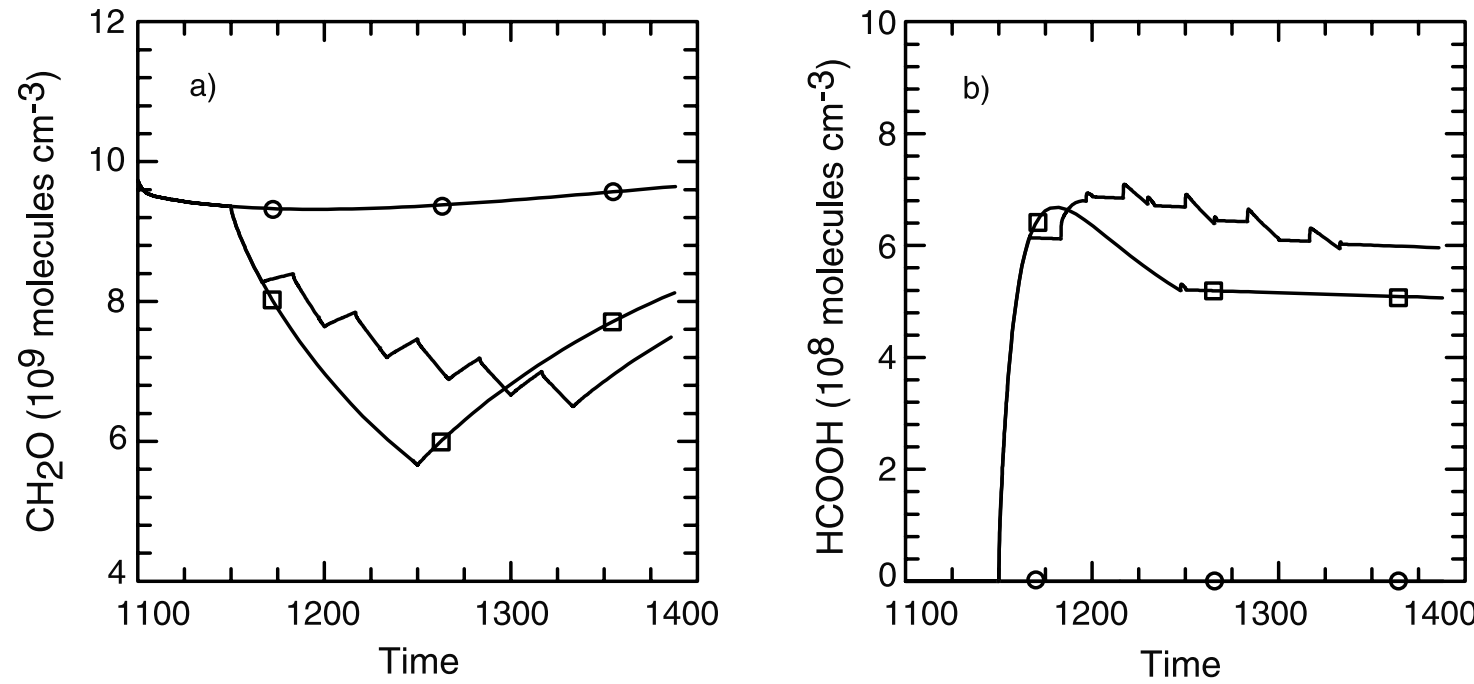

Figure 10. Total concentration of (a) $\mathrm{CH}_{2} \mathrm{O}$ and (b) $\mathrm{HCOOH}$ as a function of time under constant $\mathrm{NO}_{x}$ concentrations using the Barth-Gear model for the simulation with only gas-phase chemistry (line with circles), the continuous cloudy simulation (line with squares), and the intermittent cloudy simulation (solid line). 


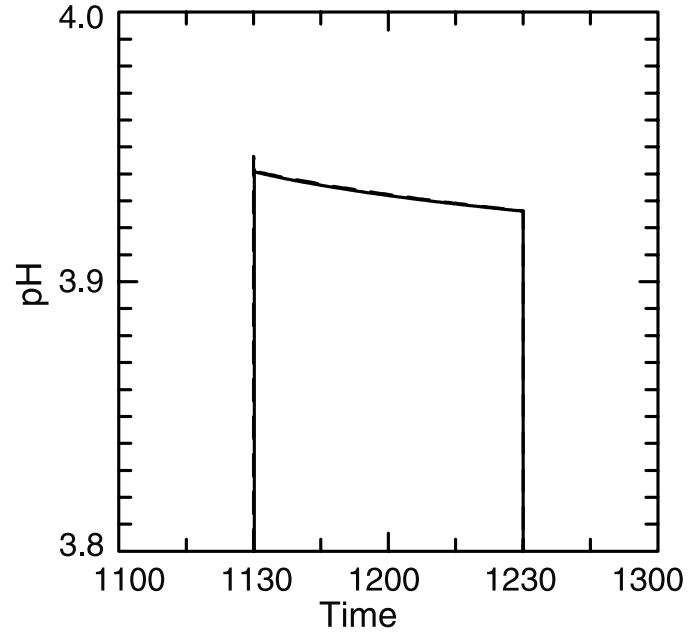

Figure 11. $\mathrm{pH}$ as a function of time for the cloudy simulation in which the $\mathrm{pH}$ was diagnosed from the chemical ions using the Kim (dashed) and Jacobson (solid) models.

al., 1989; Barth et al., 1989; Noone et al., 1991; Laj et al., 1997]. However, there is quite a bit of uncertainty if this ratio determined from measuremetns can be in Henry's law equilibrium because the aqueous-phase concentration is obtained from bulk-water samples collected over time periods of minutes to a half hour or so. Pandis and Seinfeld [1991] showed that bulk water collection of samples cannot represent the actual concentration of a species for a particular size of drop. That is, because the bulk water sample is a collection of droplets of different sizes and $\mathrm{pH}$ values the bulk sample cannot be in Henry's law even if the individual droplets are in equilibrium. In addition, because a sample of liquid water must be carried out over a period of minutes, variations of liquid water content during the sampling period cause deviations from Henry's law [Winiwarter et al., 1992; Pandis and Seinfeld, 1992].

[38] We can compare the ratios listed in Table 9 to those predicted from theoretical calculations [Jacob, 2000; Chameides, 1984]. Jacob [2000] predicts that $\mathrm{HO}_{2}, \mathrm{O}_{3}, \mathrm{NO}_{3}$, and $\mathrm{OH}$ are not in Henry's law equilibrium while other species should be in equilibrium, which is supported by our study except for the aqueous to gas concentration ratio of $\mathrm{O}_{3}$. Jacob [2000] predicts that $\mathrm{O}_{3}$ is not well-mixed in the cloud drop preventing its achievement to reach Henry's law equilibrium. In our study most models did not include the mass transport limitation of a species from the drop surface to the bulk of the liquid, thus prediction of deviations from Henry's law by $\mathrm{O}_{3}$ is not represented. The Monod model did represent mass transport limitation in the aqueous phase for the $\mathrm{OH}$ radical only (section 2.2). In section 5.2 results from the Monod model are compared with a sensitivity simulation in which mass transport limitation in the aqueous phase was not represented. Although Chameides [1984] did not discuss all the species presented in our study, he found $\mathrm{OH}$ and $\mathrm{HO}_{2}$ to be well undersaturated with respect to Henry's law, similar to our findings.

[39] Because large-scale, 3-dimensional models need to determine the partitioning of a species between gas and aqueous phases for calculations of wet deposition and aqueous chemistry when appropriate, these box model simula- tions can be used to guide how to calculate the partitioning. However, the calculation of the partitioning between gas and aqueous phases must be done with caution. The results reported here are appropriate for cloud drops that are 10 $\mu \mathrm{m}$ in radius. The deviation from Henry's law equilibrium may be larger for rain drops, which typically are $100 \mu \mathrm{m}$ or bigger in size [Leriche et al., 2001]. Although the aqueous to gas-phase ratio of $\mathrm{HNO}_{3}$ is about 7 times smaller than that predicted by equilibrium, the estimate of nearly all the $\mathrm{HNO}_{3}$ residing in the cloud drops is approximately correct and thus an assumption of $\mathrm{HNO}_{3}$ being in Henry's law equilibrium with cloud droplets is reasonable for large-scale models.

\subsection{Effect of Aqueous Phase Mass Transport Limitation}

[40] Because the Monod model did represent mass transport limitation in the aqueous phase for the $\mathrm{OH}$ radical only (section 2.2), we can compare results from the Monod model with results from a sensitivity simulation in which mass transport limitation in the aqueous phase was not represented for any species. Two time instances are considered: one-half hour after the onset of cloud for which attainment of Henry's law equilibrium can again be assessed, and at the end of the simulation at which any long-lasting effects of aqueous phase transport limitation of $\mathrm{OH}$ can be determined. We find at onehalf hour after the onset of cloud that aqueous-phase $\mathrm{O}_{3}$ and $\mathrm{OH}$ concentrations are $10 \%$ smaller when aqueous phase transport limitation of $\mathrm{OH}$ is included than when aqueous phase transport limitation is not represented and total (gas + aqueous) concentrations of $\mathrm{CH}_{2} \mathrm{O}$ and $\mathrm{HCOOH}$ are increased by about $3 \%$. Concentrations of all other species at $t=1200$ from the simulation when aqueous phase transport limitation is not represented are within $1 \%$ of the concentrations when aqueous phase transport limitation of $\mathrm{OH}$ is included. These small effects on $\mathrm{OH}, \mathrm{O}_{3}, \mathrm{CH}_{2} \mathrm{O}$, and $\mathrm{HCOOH}$ occur because at a $\mathrm{pH}=5$, the primary source of aqueous-phase $\mathrm{OH}$ is production from $\mathrm{O}_{3}$ reacting with $\mathrm{O}_{2}{ }^{-}$[Monod and Carlier, 1999] and the source from the gas-phase is smaller. At lower $\mathrm{pH}$, the $\mathrm{O}_{3}+\mathrm{O}_{2}{ }^{-}$reaction rate is smaller and aqueous-phase mass transport limitation of $\mathrm{OH}$ is more important [Monod and Carlier, 1999]. The $\mathrm{O}_{3}$ phase ratio $\left(\mathrm{C}_{a} / \mathrm{C}_{g}\right)$ with aqueousphase transport limitation of $\mathrm{OH}$ is $10 \%$ smaller than the equilibrium phase ratio $\left(K_{H} R T \mathrm{~L}\right)$. The $\mathrm{CH}_{2} \mathrm{O}$ and $\mathrm{HCOOH}$ phase ratios remain in Henry's law equilibrium.

[41] At the end of the integration $(\mathrm{t}=1300), \mathrm{O}_{3}$ and $\mathrm{OH}$ concentrations from the simulations with aqueous phase transport limitation of $\mathrm{OH}$ differ by less than $0.2 \%$ of their values from the simulation without aqueous phase transport limitation. $\mathrm{CH}_{2} \mathrm{O}$ and $\mathrm{HCOOH}$ concentrations from the simulation in which aqueous phase transport limitation of $\mathrm{OH}$ is included are $3.5 \%$ and $6.2 \%$ greater than that from the simulation in which aqueous phase transport limitation is not represented. The reduced availability of $\mathrm{OH}$ in the aqueous phase during the simulation in which aqueous phase transport limitation of $\mathrm{OH}$ is included also reduced the rate of aqueous-phase destruction of $\mathrm{CH}_{2} \mathrm{O}$ and $\mathrm{HCOOH}$.

\subsection{Effect of Aqueous Chemistry on the Total Concentration of the Species}

[42] By comparing the midpoint $(t=1200)$ of the clear sky only and the cloudy simulations, we can assess the 

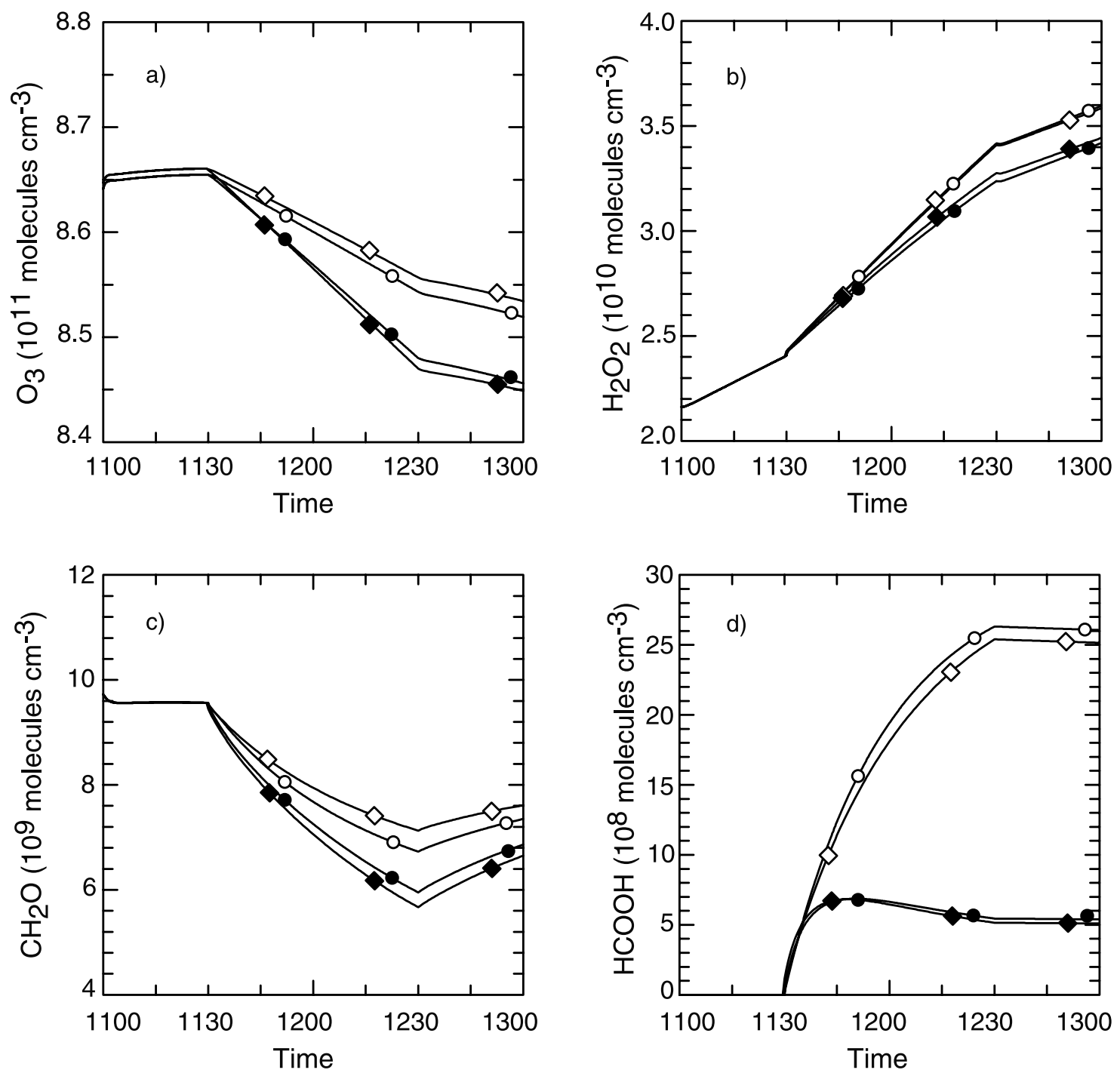

Figure 12. Total concentration of (a) $\mathrm{O}_{3}$, (b) $\mathrm{H}_{2} \mathrm{O}_{2}$, (c) $\mathrm{CH}_{2} \mathrm{O}$ and (d) $\mathrm{HCOOH}$ as a function of time for the simulation in which the $\mathrm{pH}$ was diagnosed from the chemical ions (Kim: open diamonds, Jacobson: open circles) and for the simulation in which the $\mathrm{pH}$ was prescribed to a value of 5 (Kim: solid diamonds, Jacobson: solid circles).

effect of aqueous chemistry during a cloud encounter. The last column in Table 7 shows that some species are changed substantially during the cloud episode. Total $\mathrm{OH}$ concentrations decrease by $27 \%$, total $\mathrm{CH}_{2} \mathrm{O}$ decreases by $24 \%$, and total $\mathrm{HO}_{2}$ concentrations decrease by $81 \%$. While total $\mathrm{NO}_{2}$ concentrations decrease only a little, NO concentrations increase by $23 \%$. However, as is seen in Figures $1-3$ some of these large changes are short-lived.

[43] By comparing the endpoints, which are gas-phase concentrations, of the clear sky only and the cloudy simulations, we can assess the influence of aqueous chemistry as a more lasting effect on tropospheric chemistry. Table 8 lists the percent change between the 2 simulations of each species at the end of the integration. While $\mathrm{OH}$ and $\mathrm{HO}_{2}$ show large changes during cloud, their concentrations are nearly the same for the two simulations one-half hour after cloud because their short chemical lifetime allows the gas-phase chemistry to control their concentration soon after cloud exposure. On the other hand, formaldehyde concentrations are still $27 \%$ smaller after cloud exposure than the concentrations from the clear sky simulation. Other species that are depleted by aqueous chemistry are $\mathrm{CH}_{3} \mathrm{OOH}, \mathrm{HNO}_{3}$, and $\mathrm{O}_{3}$. The species $\mathrm{H}_{2} \mathrm{O}_{2}, \mathrm{NO}$, and $\mathrm{NO}_{2}$ increase in concentration due to

Table 9. Average Ratio of Aqueous Concentration to Gas Concentration at Time $=1200$ and the Equilibrium Phase Ratio

\begin{tabular}{|c|c|c|}
\hline Species & $\frac{C_{a}}{C_{g}}$ & $K_{H} R T L$ \\
\hline $\mathrm{O}_{3}$ & $1.072( \pm 0.050) \times 10^{-7}$ & $1.097 \times 10^{-7}$ \\
\hline $\mathrm{OH}$ & $4.283( \pm 0.482) \times 10^{-5}$ & $4.191 \times 10^{-4}$ \\
\hline $\mathrm{CH}_{2} \mathrm{O}$ & $0.0636( \pm 0.0004)$ & 0.0636 \\
\hline $\mathrm{HCOOH}$ & $1.257( \pm 0.230)$ & 1.388 \\
\hline $\mathrm{HO}_{2}$ & $0.0665( \pm 0.0144)$ & 0.3116 \\
\hline $\mathrm{H}_{2} \mathrm{O}_{2}$ & $1.816( \pm 0.012)$ & 1.807 \\
\hline $\mathrm{CH}_{3} \mathrm{OO}$ & $2.478( \pm 0.017) \times 10^{-4}$ & $2.480 \times 10^{-4}$ \\
\hline $\mathrm{CH}_{3} \mathrm{OOH}$ & $4.837( \pm 0.028) \times 10^{-3}$ & $4.821 \times 10^{-3}$ \\
\hline NO & $1.681( \pm 0.009) \times 10^{-8}$ & $1.677 \times 10^{-8}$ \\
\hline $\mathrm{NO}_{2}$ & $6.600( \pm 0.035) \times 10^{-8}$ & $6.583 \times 10^{-8}$ \\
\hline $\mathrm{HNO}_{3}$ & $1.367( \pm 3.615) \times 10^{7}$ & $9.566 \times 10^{7}$ \\
\hline $\mathrm{NO}_{3}$ & $3.652( \pm 6.087) \times 10^{-6}$ & $1.715 \times 10^{-5}$ \\
\hline $\mathrm{N}_{2} \mathrm{O}_{5}$ & 0.000 & $7.016 \times 10^{6}$ \\
\hline
\end{tabular}


aqueous chemistry under the conditions specified for these required simulations.

[44] The depletion of $\mathrm{CH}_{2} \mathrm{O}$ by exposure to cloud, which is in agreement with Lelieveld and Crutzen [1990] for the same simulated case, is quite substantial and should reduce the $\mathrm{HO}_{2}$ to $\mathrm{OH}$ ratio and possibly $\mathrm{O}_{3}$ production. The $\mathrm{HO}_{2}$ to $\mathrm{OH}$ ratio is reduced by $6 \%$ for the cloudy simulation onehalf hour after the cloud has disappeared compared to the clear-sky simulation. However, there appears to be little to no effect on $\mathrm{O}_{3}$. Other modeling studies also find depletions of total $\mathrm{CH}_{2} \mathrm{O}$ [e.g., Jacob, 1986; Barth et al., 2002] during and after exposure to cloud. The $\mathrm{CH}_{2} \mathrm{O}$ depletion predicted by these modeling studies contrasts with measurements of $\mathrm{CH}_{2} \mathrm{O}$ obtained in central Virginia [Munger et al., 1995; Keene et al., 1995] and in the Po Valley of Italy [Facchini et al., 1992], which showed small or no depletion of $\mathrm{CH}_{2} \mathrm{O}$ during or after exposure to cloud/fog. Laj et al. [1997] present some evidence of $\mathrm{CH}_{2} \mathrm{O}$ depletion, but were not able to quantify their findings. All of these measurements were obtained at sites where nonmethane hydrocarbon (NMHC) chemistry cannot be neglected. Inclusion of NMHC chemistry in both the gas and aqueous phases and inclusion of sulfur chemistry may explain the discrepancies between modeled depletions of $\mathrm{CH}_{2} \mathrm{O}$ and the observed "no or little effect" on formaldehyde concentrations.

[45] Because of its importance as a major intermediate in the oxidation of hydrocarbons and because $\mathrm{CH}_{2} \mathrm{O}$ is a reservoir for radical species, the influence of clouds on $\mathrm{HO}_{x}$ and $\mathrm{NO}_{x}$ chemistry may be important. As a part of the case outlined in section 3, the Sillman model was used to investigate the effect of other gas and aqueous-phase chemistry on the species concentrations. When aqueousphase sulfur chemistry is included in the Sillman model, the results show further depletion of $\mathrm{CH}_{2} \mathrm{O}$ because of reaction of $\mathrm{CH}_{2} \mathrm{O}$ with $\mathrm{S}(\mathrm{IV})$ in the cloud drops. When gas-phase NMHC chemistry is included in the Sillman model, the total $\mathrm{CH}_{2} \mathrm{O}$ is altered during both the clear sky and cloudy periods of the integration. During the initial clear sky period, $\mathrm{CH}_{2} \mathrm{O}$ concentrations increase due to increased production of $\mathrm{CH}_{2} \mathrm{O}$ from oxidation of alkanes. During cloud the depletion of $\mathrm{CH}_{2} \mathrm{O}$ is somewhat smaller than what was found in the required cloudy simulation because of the additional gas-phase $\mathrm{CH}_{2} \mathrm{O}$ production from oxidation of alkanes. It is therefore important in future studies to quantify cloud chemistry effects on aldehydes, peroxides and the $\mathrm{HO}_{x}$ and $\mathrm{NO}_{x}$ chemistry using different chemical scenarios including nonmethane hydrocarbon chemistry.

\subsection{Future Directions of Cloud Chemistry Modeling Intercomparisons}

[46] Because the case presented here was well constrained, agreement among models proved to be very good. Having achieved this first step, the cloud chemistry modeling community should be prepared to compare simulations for other chemical scenarios such as the ones described by Poppe et al. [2001]. Chemical scenarios that include sulfur chemistry and NMHC chemistry in both the gas and aqueous phases should be represented and other scenarios such as the marine boundary layer must also be considered. As discussed in the preceding section, when other chemistry is included the response of a species to cloudy conditions may be quite different from what is reported in this study.
[47] One goal that we need to work towards is developing a suite of cloud physical and chemical observations that can readily be used for evaluation of numerical models. A fairly simple framework to accomplish this would be to simulate orographic or small cumulus clouds for which in-flow air, incloud air, and outflow air could be characterized. A simple manner of simulating these clouds would be to use a parcel model as was done for the second part of the cloud chemistry intercomparison [Kreidenweis et al., 2003]. Configuring the gas-aqueous photochemistry to a parcel model framework would be more realistic in representing an air parcel undergoing cloud conditions. A parcel model would provide a means to test the ability of numerical solution techniques to simulate changing liquid water contents which will shock the system of equations frequently. By combining aerosol physics (in particular, cloud drop activation) with the photochemistry, the chemistry and physics of an air parcel could be more realistically represented as the air parcel activates cloud drops and allows for cloud drops to grow with time. This scenario would allow effects of changing cloud drop size on the chemistry to be studied. Furthermore the $\mathrm{pH}$ of the drops could be calculated with time, allowing the chemical species to control the acidity of the drops.

[48] Other cloud-related processes should also be assessed. One process that could be addressed in the near future with appropriate observations would be the effect of cloud scattering on actinic flux and therefore photolysis frequencies similar to that presented by Matthijsen et al. [1998]. A simple framework to focus on this process may be observing and simulating the chemistry below, in and above a stratus deck.

\section{Summary}

[49] Results of Part 1 of the first cloud chemistry numerical modeling intercomparison that took place as part of the 5th International Cloud Modeling Workshop in August 2000 are reported. The intercomparison of photochemical box models show for the conditions specified that there is quite good agreement among gas-aqueous chemistry models, which are being used in the community. Therefore, we recommend the use of any of the mass-conserving numerical techniques employed in this study for cloud chemistry modeling studies in 0 to 3 dimensions.

[50] By examining the concentration of a species one-half hour after the cloud has disappeared, a longer-term effect of aqueous chemistry on species concentration was assessed. It was found that $\mathrm{CH}_{2} \mathrm{O}, \mathrm{CH}_{3} \mathrm{OOH}, \mathrm{HNO}_{3}$, and $\mathrm{O}_{3}$ are depleted by aqueous chemistry, while $\mathrm{H}_{2} \mathrm{O}_{2}$ (in the absence of sulfur chemistry), $\mathrm{NO}$, and $\mathrm{NO}_{2}$ increase in concentration. The reduced $\mathrm{CH}_{2} \mathrm{O}$ concentrations should also reduce the $\mathrm{HO}_{2}$ to $\mathrm{OH}$ ratio and possibly $\mathrm{O}_{3}$ production, but for the conditions of the simulation in this study there is little to no effect on $\mathrm{O}_{3}$ seen. The $\mathrm{HO}_{2}$ to $\mathrm{OH}$ ratio is reduced by $6 \%$ for the cloudy simulation one-half hour after the cloud has disappeared compared to the clear-sky simulation. To quantify the influence of cloud on $\mathrm{CH}_{2} \mathrm{O}$ concentrations and its effect on $\mathrm{HO}_{x}$ chemistry more realistically, nonmethane hydrocarbon chemistry and sulfur chemistry should also be represented.

[51] Because parcels of air usually flow in and out of cloud in a matter of minutes rather than remain in cloud for 
an hour, an optional simulation was performed in which frequent brief cloud encounters were represented. The total in-cloud time for the intermittent cloud simulation was set to be the same as the standard continuous cloud simulation. Representing a cloud intermittently rather than continuously does not alter the total concentration of many of the species. However we did find that $\mathrm{CH}_{2} \mathrm{O}$ and $\mathrm{HCOOH}$ concentrations are decreased and increased, respectively, because of the timing of the $\mathrm{CH}_{2} \mathrm{O}$ production during the clear-sky intervals and destruction during the cloudy intervals. Further differences between a continuous cloud simulation and an intermittent cloud simulation are expected if $\mathrm{pH}$ is allowed to vary during the cloud periods.

[52] Simulating an intermittent cloud brought out the importance of using a chemistry time step that is a multiple of the cloud time step because deviations of results from a simulation in which the chemistry time step did not coincide with the appearance and disappearance of cloud were quite large. We recommend that investigators ensure that the chemistry time step employed in their 0 to 3 dimensional model is a multiple of either the cloud physics time step or the time step used for cloud data input.

[53] Future cloud chemistry numerical modeling intercomparisons need to bring in cloud physical and chemical observations so that the models can be evaluated with observations. A simple approach to take is a Lagrangian approach, that is, to observe and simulate an air parcel that activates cloud drops and subsequently undergoes cloud drop growth and aqueous chemistry. Other cloud-related processes, such as the radiative effect of clouds on chemistry, should also be assessed.

[54] Acknowledgments. The National Center for Atmospheric Research is operated by the University Corporation for Atmospheric Research under the sponsorship of the National Science Foundation. Comments on the manuscript by Bernard Aumont and Katharine Moore are appreciated.

\section{References}

Barth, M. C., D. A. Hegg, P. V. Hobbs, J. G. Walega, G. L. Kok, B. G. Heikes, and A. L. Lazrus, Measurements of atmospheric gas-phase and aqueous-phase hydrogen peroxide concentrations in winter on the east coast of the United States, Tellus, 41, Ser. B, 61-69, 1989.

Barth, M. C., P. G. Hess, and S. Madronich, Effect of marine boundary layer clouds on tropospheric chemistry as analyzed in a regional chemistry transport model, J. Geophys. Res., 107(D11), 4126, doi:10.1029/ 2001JD000468, 2002.

Chameides, W. L., The photochemistry of a remote marine stratiform cloud, J. Geophys. Res., 89, 4739-4755, 1984.

Chance, E. M., A. R. Curtis, I. P. Jones, and C. R. Kirby, AERE Report R8775: FACSIMILE: A computer program for flow and chemistry simulation, and general initial value problems, technical report, UK Atomic Energy Authority, Harwell, 1977.

DeMore, W. B., S. P. Sander, D. M. Golden, R. F. Hampson, M. J. Kurylo, C. J. Howard, A. R. Ravishankara, C. E. Kolb, and M. J. Molina, Chemical kinetics and photochemical data for use in stratospheric modeling, JPL Publ. 97-4, 1997.

Facchini, M. C., et al., Phase-partitioning and chemical reactions of low molecular weight organic compounds in fog, Tellus, 44, Ser. B, 533-544, 1992.

Gear, C. W., Numerical Initial Value Problems in Ordinary Differential Equations, Prentice-Hall, Old Tappan, N. J., 1971.

Jacob, D. J., Chemistry of $\mathrm{OH}$ in remote clouds and its role in the production of formic acid and peroxymonosulfate, J. Geophys. Res., 91, 98079826, 1986.

Jacob, D. J., Heterogeneous chemistry and tropospheric ozone, Atmos. Environ., 34, 2131-2159, 2000.

Jacobson, M. Z., SMVGEAR II, Improvement of SMVGEAR II on vector and scalar machines through absolute error tolerance control, Atmos. Environ., 32, 791-796, 1998.
Jacobson, M. Z., Fundamentals of Atmospheric Modeling, Cambridge Univ. Press, New York, 1999.

Jacobson, M. Z., and R. P. Turco, SMVGEAR: A sparse-matrix, vectorized Gear code for atmospheric models, Atmos. Environ., 28, 273-284, 1994.

Keene, W. C., B. W. Mosher, D. J. Jacob, J. W. Munger, R. W. Talbot, R. S. Artz, J. R. Maben, B. C. Daube, and J. N. Galloway, Carboxylic acids in clouds at a high-elevation forested site in central Virginia, J. Geophys. Res., 100, 9345-9357, 1995.

Kim, C.-H., S. M. Kreidenweis, G. Feingold, G. J. Frost, and M. K. Trainer, Modeling cloud effects on hydrogen peroxide and methylhydroperoxide in the marine atmosphere, J. Geophys. Res., 107(D2), 4018, doi:10.1029/ 2000JD000285, 2002.

Kreidenweis, S. M., C. J. Walcek, G. Feingold, W. Gong, M. Z. Jacobson, C.-H. Kim, X. Liu, J. E. Penner, A. Nenes, and J. H. Seinfeld, Modification of aerosol mass and size distribution due to aqueous-phase $\mathrm{SO}_{2}$ oxidation in clouds: Comparisons of several models, J. Geophys. Res., 108, doi:10.1029/2000JD002697, in press, 2003.

Laj, P., et al., Cloud processing of soluble gases, Atmos. Environ., 31, 2589-2598, 1997.

Lelieveld, J., and P. J. Crutzen, Influences of cloud photochemical processes on tropospheric ozone, Nature, 343, 227-233, 1990.

Lelieveld, J., and P. J. Crutzen, The role of clouds in tropospheric photochemistry, J. Atmos. Chem., 12, 229-267, 1991.

Leriche, M., N. Chaumerliac, and A. Monod, Coupling quasi-spectral microphysics with multiphase chemistry: A case study of a polluted air mass at the top of the Puy de Dome mountain (France), Atmos. Environ., 35, $5411-5423,2001$.

Liang, J., and M. Z. Jacobson, A study of sulfur dioxide oxidation pathways over a range of liquid water contents, $\mathrm{pH}$ values, and temperatures, J. Geophys. Res., 104, 13,749-13,769, 1999.

Matthijsen, J., K. Suhre, R. Rosset, F. L. Eisele, R. L. Mauldin, and D. J. Tanner, Photodissociation and UV radiative transfer in a cloudy atmosphere: Modeling and measurements, J. Geophys. Res., 103, 16,665$16,676,1998$.

Monod, A., and P. Carlier, Impact of clouds on the tropospheric ozone budget: Direct effect of multiphase photochemistry of soluble organic compounds, Atmos. Environ., 33, 4431-4446, 1999.

Munger, J. W., J. Collett, B. Daube, and M. R. Hoffmann, Chemical composition of coastal stratus clouds: Dependence on droplet size and distance from the coast, Atmos. Environ., 23, 2305-2320, 1989.

Munger, J. W., D. J. Jacob, B. C. Daube, L. W. Horowitz, W. C. Keene, and B. G. Heikes, Formaldehyde, glyoxal, and methylglyoxal in air and cloudwater at a rural mountain site in central Virginia, J. Geophys. Res., 100, 9325-9333, 1995.

Noone, K. J., J. A. Ogren, K. B. Noone, A. Hallberg, S. Fuzzi, and J. A. Lind, Measurements of the partitioning of hydrogen peroxide in a stratiform cloud, Tellus, 43, Ser. B, 280-290, 1991.

Olson, J., et al., Results from the Intergovernmental Panel on Climatic Change photochemical model intercomparison (Photocomp), J. Geophys. Res., 102, 5979-5991, 1997.

Pandis, S., and J. H. Seinfeld, Should bulk cloudwater or fogwater samples obey Henry's law?, J. Geophys. Res., 96, 10,791-10,798, 1991.

Pandis, S. N., and J. H. Seinfeld, Reply to comment by W. Winiwarter et al. on"Should bulk cloudwater or fogwater samples obey Henry's law?", J. Geophys. Res., 97, 6079-6081, 1992.

Poppe, D., et al., Scenarios for modeling multiphase tropospheric chemistry, J. Atmos. Chem., 40, 77-86, 2001.

Sandu, A., F. A. Potra, G. R. Carmichael, and V. Damian, Efficient implementation of fully implicit methods for atmospheric chemical kinetics, J. Comput. Phys., 129, 101-110, 1996.

Sandu, A., J. G. Verwer, M. van Loon, G. R. Carmichael, F. A. Potra, D. Dabdub, and J. H. Seinfeld, Benchmarking stiff ODE solvers for atmospheric chemistry problems, I, Implicit vs explicit, Atmos. Environ., 31, 3151-3166, 1997.

Schwartz, S. E., Mass-transport considerations pertinent to aqueous phase reactions of gases in liquid-water clouds, in Chemistry of Multiphase Atmospheric Systems, edited by W. Jaeschke, pp. 415-471, SpringerVerlag, New York, 1986.

Sillman, S., A numerical solution to the equations of tropospheric chemistry based on an analysis of sources and sinks of odd hydrogen, J. Geophys. Res., 96, 20,735-20,744, 1991.

Verwer, J. G., J. G. Blom, M. van Loon, and E. J. Spee, A comparison of stiff ODE solvers for atmospheric chemistry problems, Atmos. Environ., 30, 49-58, 1996.

Winiwarter, W., B. Brantner, and H. Puxbaum, Comment on"Should bulk cloudwater or fogwater samples obey Henry's law?" by S. N. Pandis and J. H. Seinfeld, J. Geophys. Res., 97, 6075-6078, 1992.

M. C. Barth, National Center for Atmospheric Research, P.O. Box 3000, Boulder, CO 80307, USA. (barthm@ucar.edu) 
R. C. Hudman, Pierce Hall, Harvard University, 29 Oxford Street, Cambridge, MA 02138, USA.

M. Z. Jacobson, Department of Civil and Environmental Engineering, Stanford University, Terman Engineering Center, Room M-13, Stanford, CA 94305-4020, USA.

C.-H. Kim, National Institute of Environmental Research (NIER), Kyong-Seo-dong, Seo-gu, Incheon 404-170, Korea.
J. Liang, California Air Resources Board, P.O. Box 2815, Sacramento, CA 95812, USA.

A. Monod, Laboratoire Chimie et Environnement, Université de Provence, case 29, 3 Place Victor Hugo, F-13331 Marseilles cedex 03, France.

S. Sillman, Department of Atmospheric, Oceanic and Space Sciences, University of Michigan, 2455 Hayward Street, Room 1541C, Ann Arbor, MI 48109-2143, USA. 